\title{
Clinical and Experimental Evidences of Hydrogen Sulfide Involvement in Lead-Induced Hypertension
}

\author{
José Sérgio Possomato-Vieira, Victor Hugo Gonçalves-Rizzi (iD, \\ Regina Aparecida do Nascimento, Rodrigo Roldão Wandekin, Mayara Caldeira-Dias, \\ Jessica Sabbatine Chimini, Maria Luiza Santos da Silva, and Carlos A. Dias-Junior \\ Department of Pharmacology, Institute of Biosciences, Sao Paulo State University (UNESP), Botucatu, SP, Brazil \\ Correspondence should be addressed to Carlos A. Dias-Junior; carlosjunior@ibb.unesp.br
}

Received 6 November 2017; Revised 9 February 2018; Accepted 20 February 2018; Published 28 March 2018

Academic Editor: Wan-Liang Lu

Copyright (C) 2018 José Sérgio Possomato-Vieira et al. This is an open access article distributed under the Creative Commons Attribution License, which permits unrestricted use, distribution, and reproduction in any medium, provided the original work is properly cited.

\begin{abstract}
Lead- $(\mathrm{Pb}-)$ induced hypertension has been shown in humans and experimental animals and cardiovascular effects of hydrogen sulfide $\left(\mathrm{H}_{2} \mathrm{~S}\right)$ have been reported previously. However, no studies examined involvement of $\mathrm{H}_{2} \mathrm{~S}$ in $\mathrm{Pb}$-induced hypertension. We found increases in diastolic blood pressure and mean blood pressure in $\mathrm{Pb}$-intoxicated humans followed by diminished $\mathrm{H}_{2} \mathrm{~S}$ plasmatic levels. In order to expand our findings, male Wistar rats were divided into four groups: Saline, $\mathrm{Pb}, \mathrm{NaHS}$, and $\mathrm{Pb}+\mathrm{NaHS}$. $\mathrm{Pb}$-intoxicated animals received intraperitoneally (i.p.) 1st dose of $8 \mu \mathrm{g} / 100 \mathrm{~g}$ of Pb acetate and subsequent doses of $0.1 \mu \mathrm{g} / 100 \mathrm{~g}$ for seven days and sodium hydrosulfide- (NaHS-) treated animals received i.p. NaHS injections ( $50 \mu \mathrm{mol} / \mathrm{kg} / \mathrm{twice}$ daily) for seven days. NaHS treatment blunted increases in systolic blood pressure, increased $\mathrm{H}_{2} \mathrm{~S}$ plasmatic levels, and diminished whole-blood lead levels. Treatment with $\mathrm{NaHS}$ in $\mathrm{Pb}$-induced hypertension seems to induce a protective role in rat aorta which is dependent on endothelium and seems to promote non-NO-mediated relaxation. $\mathrm{Pb}$-intoxication increased oxidative stress in rats, while treatment with NaHS blunted increases in plasmatic MDA levels and increased antioxidant status of plasma. Therefore, $\mathrm{H}_{2} \mathrm{~S}$ pathway may be involved in $\mathrm{Pb}$-induced hypertension and treatment with NaHS exerts antihypertensive effect, promotes non-NO-mediated relaxation, and decreases oxidative stress in rats with $\mathrm{Pb}$-induced hypertension.
\end{abstract}

\section{Introduction}

Lead $(\mathrm{Pb})$ is an important environmental pollutant that presents hazardous effects for human health. Most of the population must have lead in their organisms due to occupational or environmental exposure [1-3]. A variety of harmful effects may arise from lead intoxication, which include alterations in bone density $[4,5]$ and cognitive $[6,7]$ and cardiovascular disorders, such as hypertension $[8,9]$, and these adverse effects may result from both duration of exposure and blood lead levels [10]. The National Institute for Occupational Safety and Health, USA, stated that reference blood lead levels for adults should be $\geq 5 \mu \mathrm{g} / \mathrm{dL}$ [11] and lead-induced hypertension has been shown in experimental animals with low blood lead levels $(9-37 \mu \mathrm{g} / \mathrm{dL})$ [9, 1214]. Multiple mechanisms have been proposed to explain how lead intoxication impairs the cardiovascular system and leads to hypertension. Although these alterations promoted by lead are not completely understood in the early stages of lead exposure, increases in angiotensin II levels resulting from converting enzyme activation [15], increases in matrix metalloproteinases levels/activity $[9,16]$, increases in cyclooxygenase-derived contractile prostanoids [12], reductions in nitric oxide (NO) bioavailability $[9,13,17]$, and increases in reactive oxygen species (ROS) production $[18,19]$ have been proposed as mechanisms involved in lead-induced hypertension.

Hydrogen sulfide $\left(\mathrm{H}_{2} \mathrm{~S}\right)$ was formerly known as a pollutant gas with characteristic smell of rotten eggs. Now, there is a large body of literature that indicates $\mathrm{H}_{2} \mathrm{~S}$ as a gasotransmitter with important physiological functions [2025]. $\mathrm{H}_{2} \mathrm{~S}$ is enzymatically produced by cystathionine $\gamma$-lyase 
(CSE) and cystathionine $\beta$-synthase (CBS) [26], though other systems have been described as $\mathrm{H}_{2} \mathrm{~S}$ producers, such as the 3-mercaptopyruvate sulfurtransferase pathway [27]. $\mathrm{H}_{2} \mathrm{~S}$ has been described to participate in several physiological processes, such as neurotransmission, inflammation and immune reactions, gastrointestinal function, cancer development, and cardiovascular responses [20, 28, 29]. Some studies report that $\mathrm{H}_{2} \mathrm{~S}$ may exert a vasodilator effect $[30,31]$ and thus help in the control of vascular tone. Moreover, $\mathrm{H}_{2} \mathrm{~S}$ may act as an antioxidant $[32,33]$. It has been shown that $\mathrm{H}_{2} \mathrm{~S}$ displayed an effective preservation of antioxidants enzymes activity [34-36] and also decreased the levels of different biomarkers of oxidative stress in vivo and in vitro [34-38]. There are evidences that $\mathrm{H}_{2} \mathrm{~S}$ exerts a vasoprotective effect in hypertension and atherosclerosis $[39,40]$ and that exogenous donors of $\mathrm{H}_{2} \mathrm{~S}$ can attenuate vascular dysfunction [41]. Importantly, to our knowledge, no studies have evaluated the role of $\mathrm{H}_{2} \mathrm{~S}$ in $\mathrm{Pb}$-induced hypertension.

As consistent vasoconstriction and increases in oxidative stress are well-known hallmarks of hypertension and $\mathrm{Pb}$ induced hypertension has been previously reported, we hypothesized that low-lead-level intoxication causes hypertension and reduces $\mathrm{H}_{2} \mathrm{~S}$ plasmatic levels in humans. In order to advance in the knowledge of $\mathrm{H}_{2} \mathrm{~S}$ role in $\mathrm{Pb}$-induced hypertension, we suggested that sodium hydrosulfide (NaHS), a donor of $\mathrm{H}_{2} \mathrm{~S}$, blunts the increases in systolic blood pressure (SBP) caused by low-lead-level intoxication in rats and that this beneficial effect on blood pressure may be related to $\mathrm{H}_{2} \mathrm{~S}$ antioxidant capacity.

\section{Materials and Methods}

2.1. Blood Pressure Measurements and Blood Collection in Human Subjects. Subjects were recruited from the Center for Toxicological Assistance (CEATOX)/UNESP, Botucatu. Written informed consent was obtained from all subjects, and the study was approved by the committee and Institutional Review Board of the Faculdade de Medicina de Botucatu, UNESP (protocol number: 16354513.0.0000.5411). Only male patients were included in this study. Blood pressure measurements were accessed in left arm using an automated device (Z-40, Techline, São Paulo, Brazil). Whole-blood heparin and plasma heparin were collected to perform lead levels analysis and biochemical assays, respectively. Samples were stored at $-80^{\circ} \mathrm{C}$. Patients with whole-blood lead levels less than $5 \mu \mathrm{g} / \mathrm{dL}$ were included as patients from control group $(n=25)$ and patients with whole-blood lead levels more than $5 \mu \mathrm{g} / \mathrm{dL}$ were included as $\mathrm{Pb}$-intoxicated group $(n=20)$.

2.2. Animals and Treatments. Forty male Wistar rats weighing approximately $250 \pm 20 \mathrm{~g}$ were used in this study. Animals were kept in standard rat cages, maintained under controlled temperature $\left(22^{\circ} \mathrm{C}\right)$ on a 12-hour light-dark cycle, and given free access to water and rat chow. All procedures for animal experimentation were approved by Ethics Committee, Institute of Biosciences, Sao Paulo State University, Botucatu (protocol number: 458/2013), which complied with international guidelines of the European Community for the use of experimental animals.
The animals were randomly divided into two leadexposed groups ( $\mathrm{Pb}$ and $\mathrm{Pb}+\mathrm{NaHS} ; n=12$ per group) and two control (non-lead-exposed) groups (Saline and NaHS; $n=8$ per group) for eight days. Animals exposed to lead were injected intraperitoneally (i.p.) with a first dose of $8 \mu \mathrm{g} / 100 \mathrm{~g}$ of lead acetate $\left(\mathrm{Pb}\left(\mathrm{C}_{2} \mathrm{H}_{3} \mathrm{O}_{2}\right)_{2}+3 \mathrm{H}_{2} \mathrm{O}, 100 \%\right.$ purity, Merck, USA) and subsequent daily doses of $0.1 \mu \mathrm{g} / 100 \mathrm{~g}$ to cover daily loss and treatment with NaHS $(50 \mu \mathrm{mol} / \mathrm{Kg} / \mathrm{twice}$ daily; $\mathrm{Pb}+\mathrm{NaHS}$ group) or vehicle (water; $\mathrm{Pb}$ group) i.p. for seven days. Animals from control groups (non-leadexposed) were injected i.p. with a first dose of $8 \mu \mathrm{g} / 100 \mathrm{~g}$ of sodium acetate $\left(\mathrm{Na}\left(\mathrm{C}_{2} \mathrm{H}_{3} \mathrm{O}_{2}\right)+3 \mathrm{H}_{2} \mathrm{O}, 99 \%\right.$ purity, J.T.Baker, Canada), a subsequent dose of $0.1 \mu \mathrm{g} / 100 \mathrm{~g}$ to cover daily loss, and treatment with $\mathrm{NaHS}(50 \mu \mathrm{mol} / \mathrm{Kg} /$ twice daily; NaHS group) or vehicle (water; Saline group) i.p. for seven days. The protocol of intoxication with lead acetate used in this study was based on previous studies $[9,13,17]$.

On the eighth day (i.e., 24 hours after each respective treatment), animals were anesthetized with isoflurane (2-4\%) and killed by exsanguination. After thoracotomy, the descending thoracic aortas were removed for vascular experiments studies. Whole-blood samples were collected in tubes containing lyophilized heparin (Vacutainer BD, trace metal-free) to access lead concentrations. Blood was also collected in tubes containing ethylenediaminetetraacetic acid (EDTA) (Vacutainer Becton-Dickinson, Oxford, UK) and sodium citrate (Vacutainer Becton-Dickinson, Oxford, UK) for plasma separation. Plasma was stored at $-80^{\circ} \mathrm{C}$ until biochemical analyses.

2.3. Blood Pressure Measurements. SBP (mmHg) was measured using tail-cuff plethysmography (Insight, Ribeirao Preto, Sao Paulo, Brazil). Briefly, conscious rats were first acclimated in a quiet room, conditioned, and restrained for 5-10 minutes in a warm box (Insight, Ribeirao Preto, Sao Paulo, Brazil). Animals were "trained" to the measurements process for 3 days before the beginning of the treatments (data were discarded). SBP was measured, and the mean of three measurements was recorded from day one to day seven of the experimental protocol, as previously described $[9,13]$. Blood pressure measurements were performed one hour before the injections of sodium acetate/ $\mathrm{Pb} / \mathrm{NaHS}$.

2.4. Determination of Lead Concentrations in Whole Blood. $\mathrm{Pb}$ concentration in whole blood from human patients and rats was determined by graphite furnace atomic absorption spectrometry (GF-AAS; Varian SpectrAA 220) as previously described $[9,13]$. Briefly, blood samples were diluted $1+$ 49 with a diluent solution containing $0.5 \%(\mathrm{v} / \mathrm{v})$ doubledistilled $\mathrm{HNO}_{3} 25 \mu \mathrm{g} / \mathrm{l} \mathrm{Rh}$ and $0.005 \%$ (v/v) Triton ${ }^{\circledR} \mathrm{X}-100$. Calibration was performed against matrix matching. The detection limit of the method was $0.5 \mu \mathrm{g} / \mathrm{L}$. The whole-blood lead concentrations were expressed in $\mu \mathrm{g} / \mathrm{dL}$.

2.5. Determination of $\mathrm{H}_{2} \mathrm{~S}$ in Plasma. Plasma obtained from human patients and experimental animals was used for the determination of $\mathrm{H}_{2} \mathrm{~S}$ as described previously [42, 43]. In brief, $75 \mu \mathrm{L}$ of plasma was mixed with $250 \mu \mathrm{L}$ of zinc acetate $1 \%$ (wt/vol) and $425 \mu \mathrm{L}$ of water. To the mixture, $150 \mu \mathrm{L}$ 
of $20 \mathrm{mmol} / \mathrm{L}$ of $\mathrm{N}$-dimethyl-p-phenylenediamine sulfate in $\mathrm{HCl} 7.2 \mathrm{M}$ and $150 \mu \mathrm{L}$ of $30 \mathrm{mmol} / \mathrm{L}$ of $\mathrm{FeCl}_{3}$ in $\mathrm{HCl} 1.2 \mathrm{M}$ were added. After 10 minutes of incubation at room temperature, $250 \mu \mathrm{L}$ of $10 \%$ trichloroacetic acid was added to remove proteins and the reaction mixture was centrifuged at $12000 \mathrm{~g}$ for 15 minutes. The absorbance of the resulting supernatant $(200 \mu \mathrm{L})$ was measured at $670 \mathrm{~nm}$ with a spectrophotometer (Synergy 4, BioTek, Winooski, VT, USA) in a 96-well plate. The concentration of $\mathrm{H}_{2} \mathrm{~S}$ in the solution was calculated against a calibration curve of NaHS $(100-3.13 \mu \mathrm{M})$.

2.6. Vascular Reactivity. Rats' thoracic aortas were dissected in 3-4 mm segments (two rings). One of the rings had its endothelium mechanically removed. The rings were mounted into a $10 \mathrm{~mL}$ organ chamber containing Krebs-Henseleit solution $\left(\mathrm{NaCl} 130 ; \mathrm{KCl} 4.7 ; \mathrm{CaCl}_{2} 1.6 ; \mathrm{KH}_{2} \mathrm{PO}_{4} 1.2 ; \mathrm{MgSO}_{4}\right.$ 1.2; $\mathrm{NaHCO}_{3}$ 15; glucose 11.1; in mmol/L) and suspended between two wire hooks; one hook was fixed to a stationary support, and the other hook connected to an isometric force transducer. The Krebs-Henseleit solution was kept at $\mathrm{pH} 7.4$ and $37^{\circ} \mathrm{C}$ and bubbled continuously with a mixture of $95 \% \mathrm{O}_{2}$ and $5 \% \mathrm{CO}_{2}$. Arterial rings were stretched under $1.5 \mathrm{~g}$ basal tension and were allowed to equilibrate for $45 \mathrm{~min}$. Changes in aorta tension were recorded using FORT10 isometric force transducers (WPI, USA) connected to Transbridge 4M Transducer Amplifier (WPI, USA) connected to a PC-based MP100 System and analyzed offline using AcqKnowledge version 3.5.7 software (Biopac Systems Inc., USA).

After tissue equilibration, a control contraction to $96 \mathrm{mM}$ of $\mathrm{KCl}$ was elicited. Once $\mathrm{KCl}$ maximum contraction was reached, tissue was rinsed with Krebs 3 times, 15 minutes each. Then, aorta rings were stimulated with increasing concentrations of phenylephrine (PHE, $10^{-10}$ to $\left.10^{-4} \mathrm{M}\right)$. In order to investigate endothelial function, vascular tissues were precontracted with $\mathrm{PHE}\left(10^{-6} \mathrm{M}\right.$ for intact rings and $3 \times 10^{-7} \mathrm{M}$ for denuded rings); increasing concentrations of acetylcholine ( $\mathrm{ACh}, 10^{-9}$ to $10^{-5} \mathrm{M}$ ) were added to the bath. To evaluate the participation of endothelium-dependent NO in aortic rings relaxation, concentration-response curves to ACh were obtained in the presence of $\mathrm{N} \omega$-nitro-Larginine-methyl ester (L-NAME, $3 \times 10^{-4} \mathrm{M}$ ), added in the last 30-minute stabilization period [44, 45]. Concentrationcontraction curves were constructed, and the maximal response to $\mathrm{PHE}$ was measured. Concentration-effect curves to $\mathrm{ACh}$, with or without L-NAME, were expressed as the $\%$ relaxation to $\mathrm{PHE}$ contraction. Nonlinear regression (variable slope) of the obtained concentration-effect curves revealed $R_{\max }$ (maximal response) and pEC50 (negative logarithm of the concentration that evoked $50 \%$ of the maximal response).

2.7. Cell Culture and Plasma Incubation. Human umbilical vein endothelial cell (HUVEC) line (CRL 2873) was obtained from American Type Culture Collection (ATCC) (Manassas, VA, USA). HUVECs were cultured in DMEM medium (Gibco, CA, USA) supplemented with $10 \%(\mathrm{v} / \mathrm{v})$ fetal calf serum (FCS) (Gibco), $50 \mu \mathrm{g} / \mathrm{ml}$ penicillin, $50 \mu \mathrm{g} / \mathrm{ml}$ streptomycin, and $0.5 \mu \mathrm{g} / \mathrm{ml}$ amphotericin $\mathrm{B}$ (Gibco) at $37^{\circ} \mathrm{C}$ in $5 \% \mathrm{CO}_{2}$ incubator. After reaching $80 \%$ confluence, HUVECs were resuspended in DMEM medium and replated in 96-well tissue culture plates (Corning), where they were grown to $80 \%$ confluence for incubation experiments. Then, the medium was removed and cells were washed twice in PBS. Cells were incubated in medium, without FCS, with 5\% (v/v) plasma from rats treated with Saline, $\mathrm{NaHS}, \mathrm{Pb}$, and $\mathrm{Pb}+$ $\mathrm{NaHS}$ for $24 \mathrm{~h}$. Cell viability was performed by MTT assay as described previously [46]. Viability was compared to control (untreated cells, $100 \%$ viability). Cell culture supernatant (CCS) was then stored and kept at $-80^{\circ} \mathrm{C}$ for posterior analysis.

2.8. Determination of Nitrite in Culture Supernatant and Plasmatic Nitrite/Nitrate (Total NOx). Nitrite levels were assessed in HUVECs culture supernatant in duplicate using Griess reagents [47]. Briefly, $50 \mu \mathrm{L}$ of samples was incubated with $50 \mu \mathrm{L}$ of $1 \%$ sulfanilamide solution in $5 \%$ phosphoric acid for 10 minutes protected from light. Then, $50 \mu \mathrm{L}$ of $0.1 \% \mathrm{~N}$ (1-Naphthyl)-ethylenediamine dihydrochloride solution was added followed by 10 -minute incubation. Plate was read in spectrophotometer (Synergy 4, BioTek, Winooski, VT) at $540 \mathrm{~nm}$. A standard curve was generated by incubation of nitrite solutions $(0.46-29.5 \mu \mathrm{mol} / \mathrm{L})$ with the previous reagents.

Plasma total NO $x$ concentrations were determined using Griess reagents followed by reduction of nitrous species with vanadium chloride III [48]. Briefly, before addition of Griess reagents, plasma was incubated with $100 \mu \mathrm{L}$ of saturated solution of vanadium chloride III for 3 hours at $37^{\circ} \mathrm{C}$ with agitation. Absorbance at $535 \mathrm{~nm}$ was read at spectrophotometer (Synergy 4, BioTek, Winooski, VT) and NOx concentrations in plasma were calculated using a standard curve of sodium nitrite $(1.56-100 \mu \mathrm{M})$. Nitrite levels in HUVECs supernatant and total NOx levels in plasma were expressed in $\mu \mathrm{mol} / \mathrm{L}$.

2.9. Determination of Lipid Peroxidation. Lipid peroxidation was determined in rats' plasma through the formation of malondialdehyde (MDA). MDA reacts with 2-thiobarbituric acid (TBA) and produces a colorimetric reaction that is measured by spectrophotometer at wavelength of $532 \mathrm{~nm}$ [49]. In test tubes, a reaction mixture containing $100 \mu \mathrm{L}$ of distilled water, $50 \mu \mathrm{L}$ of $8.1 \%$ sodium dodecyl sulfate (SDS), $100 \mu \mathrm{L}$ of plasma samples, $375 \mu \mathrm{L}$ of acetic acid $20 \%$, and $375 \mu \mathrm{L}$ of TBA $0.8 \%$ was incubated in water bath at $95^{\circ} \mathrm{C}$ for one hour and subsequently centrifuged at $4000 \mathrm{rpm}$ for 10 minutes. Standard curve was prepared in a similar manner, replacing samples with $25 \mu \mathrm{L}$ of known concentrations of MDA. Plasmatic TBA reactive species (TBARS) were calculated against a standard curve of MDA (20-320 nmol). Results were expressed as plasma MDA levels in $\mathrm{nmol} / \mathrm{mL}$.

2.10. Evaluation of the Plasmatic Antioxidant Status. Direct reductions of MTT (3-(4,5-dimethylthiazol-2-yl)-2,5-diphenyltetrazolium bromide, Sigma, St Louis, MO, USA) were assessed to determine the antioxidant status of rats' plasma, as previously described [50]. Briefly, $12.5 \mu \mathrm{L}$ of dye solution $(5 \mathrm{mg} / \mathrm{mL}$ in PBS) was mixed with $100 \mu \mathrm{L}$ of plasma and final volume was adjusted to $200 \mu \mathrm{L}$ with PBS. Reaction mixture was incubated for $60 \mathrm{~min}$ at $37^{\circ} \mathrm{C}$ and then the reaction was terminated by the addition of $750 \mu \mathrm{L}$ of $0.04 \mathrm{M}$ hydrochloric 


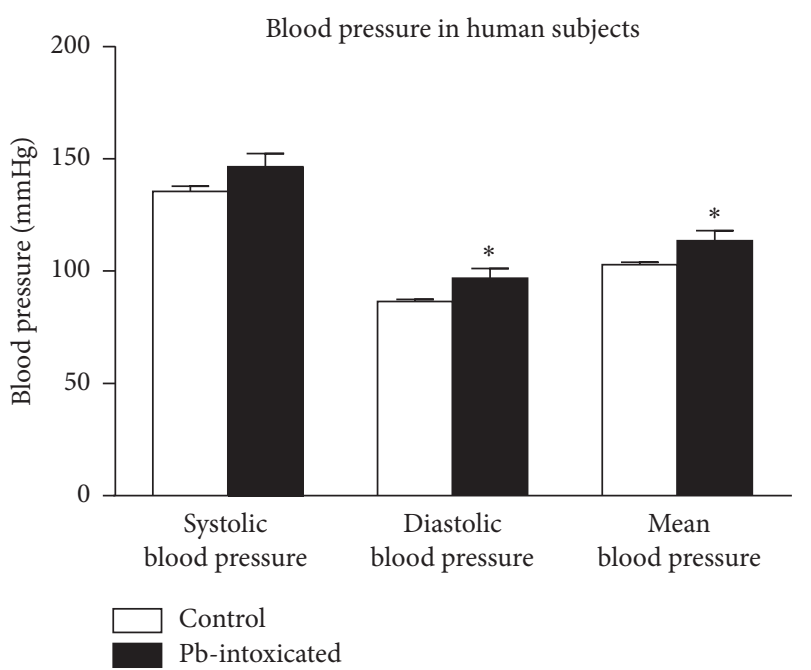

(a)

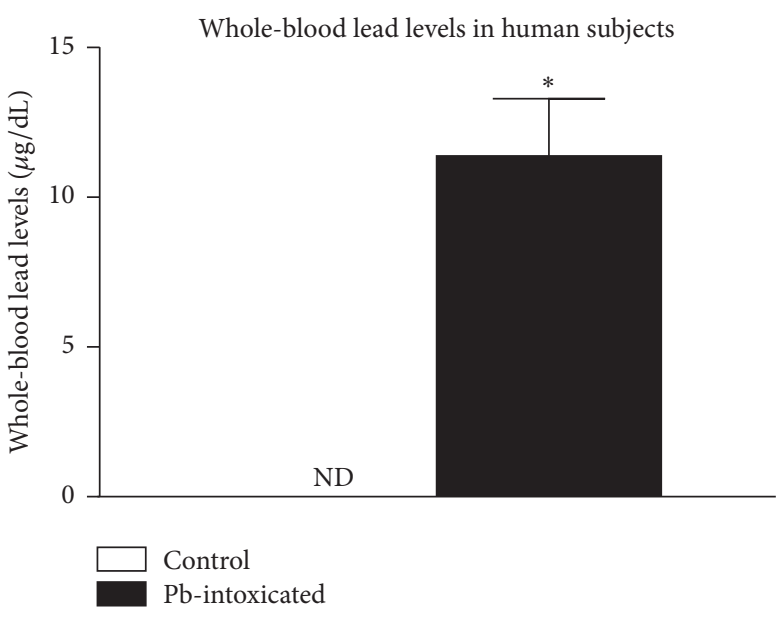

(b)

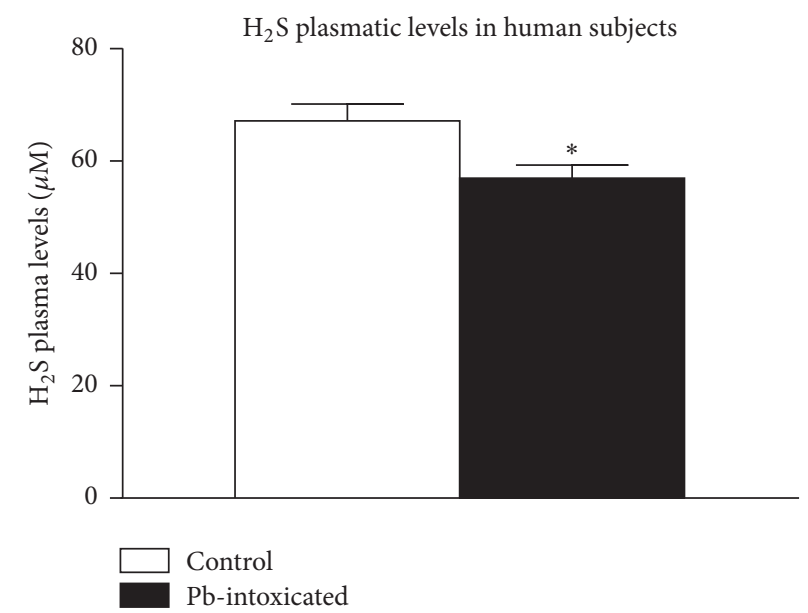

(c)

FiguRE 1: Blood pressure parameters and biochemical analysis in humans. (a) Systolic, diastolic, and mean blood pressure of control and $\mathrm{Pb}$-contaminated patients. (b) Whole-blood lead levels of control and Pb-contaminated patients. (c) $\mathrm{H}_{2} \mathrm{~S}$ plasmatic levels of control and $\mathrm{Pb}$-contaminated patients. Values represent mean \pm SEM. $n=20-25$. "ND" means nondetectable. ${ }^{*} P<0.05$ versus control group.

acid in isopropanol. Tubes were centrifuged for $10 \mathrm{~min}$ at $1000 \mathrm{~g}$ and the absorbance of the collected supernatant was measured at $570 \mathrm{~nm}$. Results are expressed as \% of control group (Saline group taken as $100 \%$ of antioxidant status).

2.11. Data Analysis and Statistics. Statistical analyses were performed using GraphPad Prism ${ }^{\circledR} 6.0$ software (San Diego, $\mathrm{CA}$ ). The results are expressed as means \pm SEM. For human parameters, comparisons were made using Student's $t$-test. Comparisons between animal groups were assessed by one-way analysis of variance (ANOVA) followed by Tukey's test. For vascular reactivity experiments, individual concentration-contraction or concentration-relaxation curves were constructed; sigmoidal curves were fitted to the data using the least square method, and the comparisons among $R_{\max }$ and $\mathrm{pEC}_{50}$ values were determined by ANOVA followed by Tukey's test. A $P<0.05$ was considered significant.

\section{Results}

3.1. Pb-Intoxication Is Related to Increased Blood Pressure and Decreased $\mathrm{H}_{2} \mathrm{~S}$ Levels in Human Subjects. Hypertension has been reported previously as a consequence of $\mathrm{Pb}$-intoxication; however, no linkage has been made with hydrogen sulfide levels. In our study, there were no significant differences in SBP in humans intoxicated with $\mathrm{Pb}(146 \pm$ $5 \mathrm{mmHg})$ compared to control subjects $(135 \pm 3 \mathrm{mmHg})$ $(P=0.08$, Figure $1(\mathrm{a}))$. However, diastolic blood pressure and mean blood pressure from patients intoxicated with $\mathrm{Pb}(96 \pm 4$ and $113 \pm 4 \mathrm{mmHg}$, resp.) were higher than diastolic blood pressure and mean blood pressure of control subjects ( $86 \pm 1$ and $102 \pm 2 \mathrm{mmHg}$, resp. $)(P=0.02$ and $P=0.02$, resp., Figure 1(a)). The values of whole-blood lead levels in $\mathrm{Pb}$ intoxicated subjects were $11.38 \pm 1.92 \mu \mathrm{g} / \mathrm{dL}$ and whole-blood lead levels in control group were below the limit of detection of the technique $(P=0.0002$, Figure $1(b))$. Plasmatic $\mathrm{H}_{2} \mathrm{~S}$ 


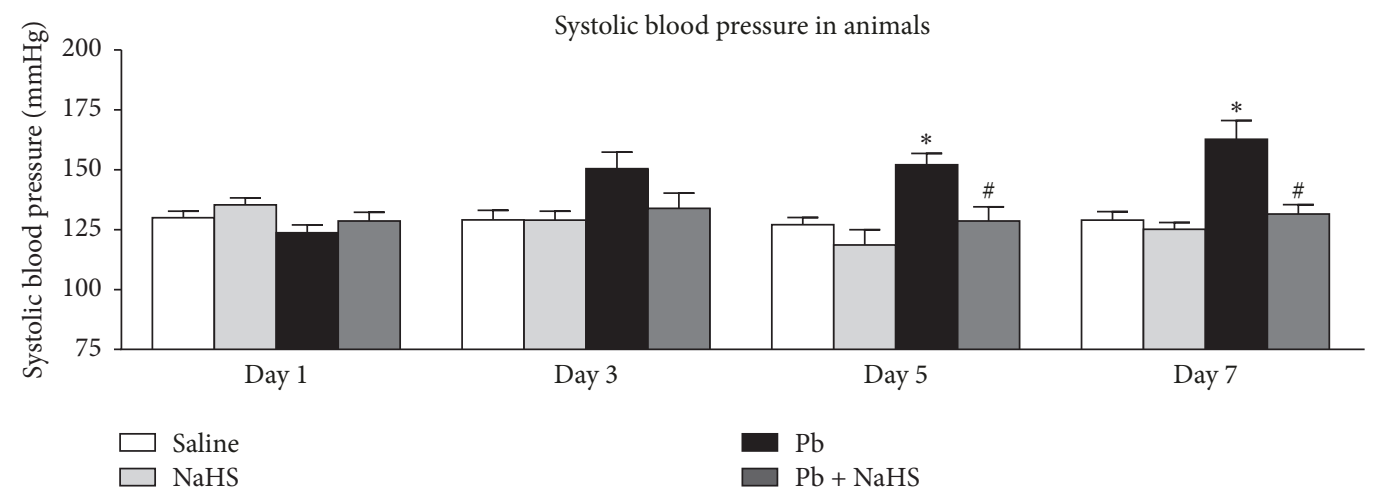

(a)

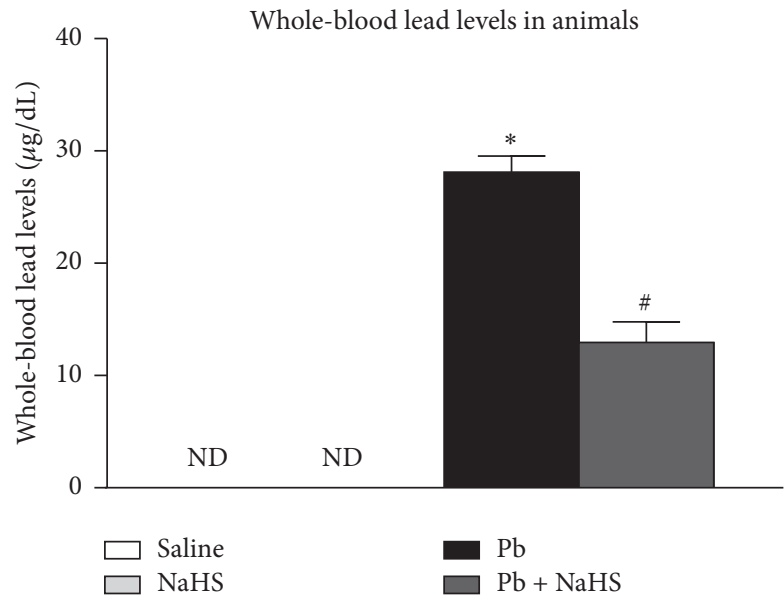

(b)

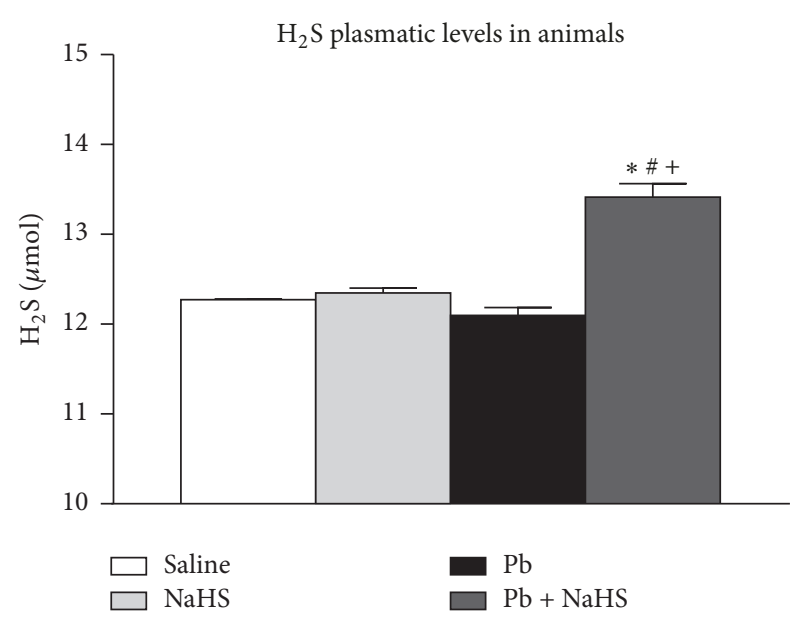

(c)

Figure 2: Blood pressure parameters and biochemical analysis in rats among four different groups: Saline (non- $\mathrm{Pb}$-exposed), NaHS (non-Pb-exposed $+\mathrm{NaHS}), \mathrm{Pb}$ (Pb-exposed), and $\mathrm{Pb}+\mathrm{NaHS}$ (Pb-exposed $+\mathrm{NaHS})$. (a) Systolic blood pressure measured with tail-cuff plethysmography on days 1, 3, 5, and 7 of experimental protocol. (b) Whole-blood lead levels measured after 7 days of $\mathrm{Pb}$ exposition. (c) $\mathrm{H}_{2} \mathrm{~S}$ plasmatic levels. Values represent mean \pm SEM. $n=6-12 .{ }^{*} P<0.05$ versus Saline group; ${ }^{\#} P<0.05$ versus $\mathrm{Pb}$ group; ${ }^{+} P<0.05$ versus NaHS group.

levels in control group were $67.15 \pm 2.99 \mu \mathrm{M}$, whereas subjects from $\mathrm{Pb}$-intoxicated group presented lower $\mathrm{H}_{2} \mathrm{~S}$ plasmatic levels $(56.99 \pm 2.28 \mu \mathrm{M})(P=0.01$, Figure $1(\mathrm{c}))$.

\subsection{NaHS Treatment Blunts Pb-Induced Hypertension in} Rats and Reduces Whole-Blood Lead Levels. In order to better understand the involvement of $\mathrm{H}_{2} \mathrm{~S}$ in $\mathrm{Pb}$-induced hypertension, we performed experiments in rats. There were no significant differences in SBP among four groups in day one (123 to $132 \pm 3 \mathrm{mmHg}$, Figure 2(a)) and day three (129 to $150 \pm 7 \mathrm{mmHg}$, Figure 2(a)). Animals from $\mathrm{Pb}$ group showed an increase in SBP versus Saline on days five (152 \pm 5 versus $127 \pm 3 \mathrm{mmHg}, P=0.007$, Figure $2(\mathrm{a}))$ and seven $(163 \pm 8$ versus $129 \pm 3 \mathrm{mmHg}, P=0.001$, Figure 2(a)). Moreover, this increase was blunted by treatment with NaHS on days five $(128 \pm 6 \mathrm{mmHg}, P=0.007$, Figure $2(\mathrm{a}))$ and seven $(131 \pm 4 \mathrm{mmHg}, P=0.0007$, Figure $2(\mathrm{a}))$.

No lead was detected in whole blood of animals from groups Saline and NaHS in the end of seven days of experimental protocol; however, rats from $\mathrm{Pb}$ group presented whole-blood lead levels of $28.12 \pm 1.45 \mu \mathrm{g} / \mathrm{dL}$ and an approximately 2 -fold decrease was found in animals from $\mathrm{Pb}+$ NaHS group $(12.96 \pm 1.81 \mu \mathrm{g} / \mathrm{dL}, P=0.001$, Figure 2(b)). $\mathrm{H}_{2} \mathrm{~S}$ levels in plasma were significantly higher in group $\mathrm{Pb}+$ NaHS $(13.42 \pm 0.15 \mu \mathrm{mol})$ versus Saline $(P=0.0001)$, NaHS $(P=0.0001)$, and $\mathrm{Pb}$ groups $(P=0.0001)(12.27 \pm 0.01,12.35$ \pm 0.05 , and $12.10 \pm 0.08 \mu \mathrm{mol}$, resp., Figure $2(\mathrm{c}))$.

3.3. Protective Effect of NaHS Treatment on Vascular PHEInduced Contraction in Hypertensive Animals Is Dependent on Endothelium. Vascular reactivity experiments were performed to assess direct vascular responses among the four different animal groups. KCl-induced contraction was not different between the experimental groups in aortic rings with $(+E)$ or without $(-E)$ endothelium (Figures 3(a)-3(b), Table 1$)$. No differences in maximum response $\left(R_{\max }\right)$ to PHE-induced contraction were observed between Saline, $\mathrm{Pb}$, and $\mathrm{Pb}+\mathrm{NaHS}$ groups in endothelium intact rings; however, greater $R_{\max }$ was reached in NaHS versus $\mathrm{Pb}(P=0.0035)$ and $\mathrm{Pb}+\mathrm{NaHS}(P=0.0077)$ groups (Figure $3(\mathrm{c})$, Table 1$)$. 


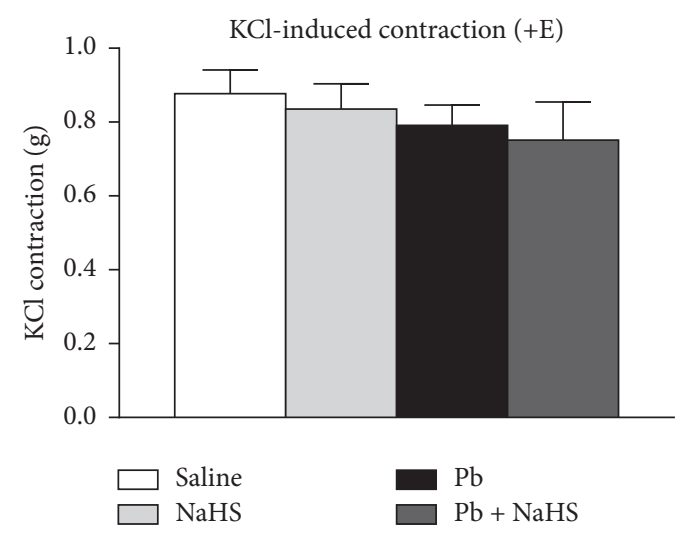

(a)

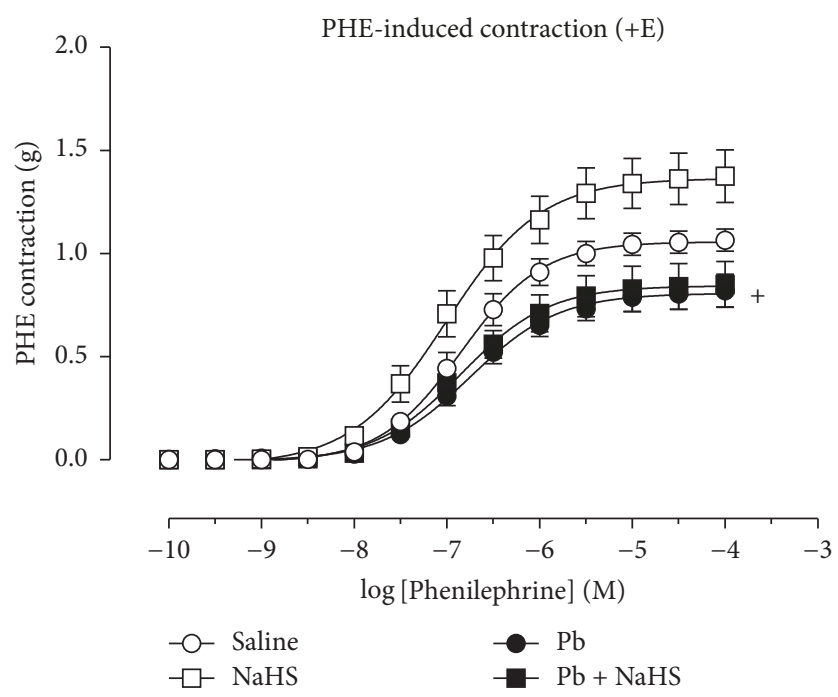

(c)

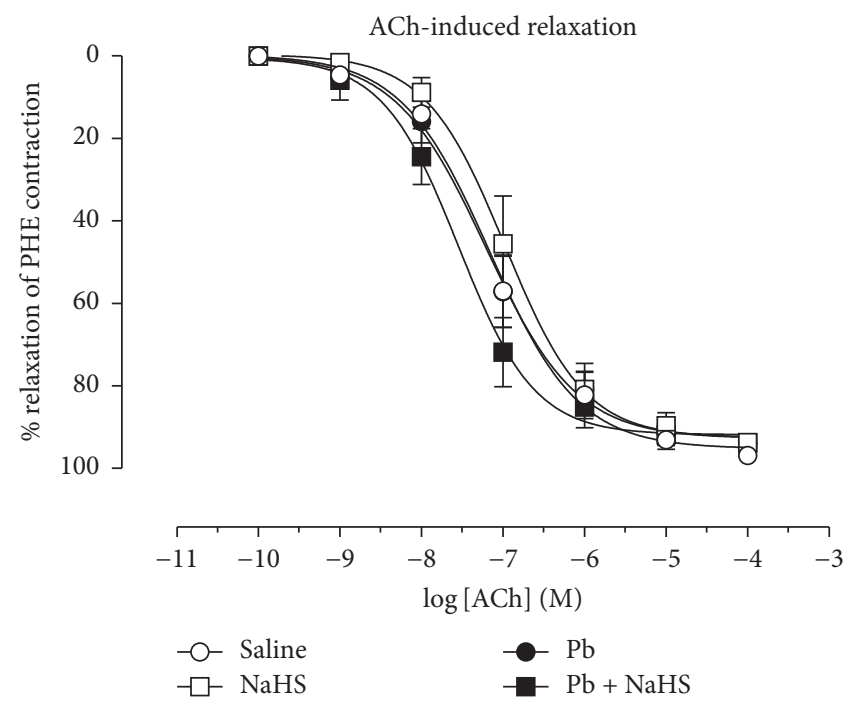

(e)

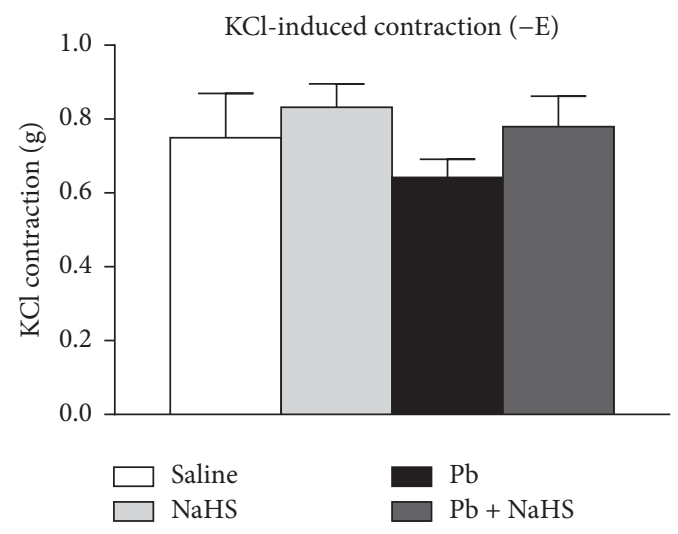

(b)
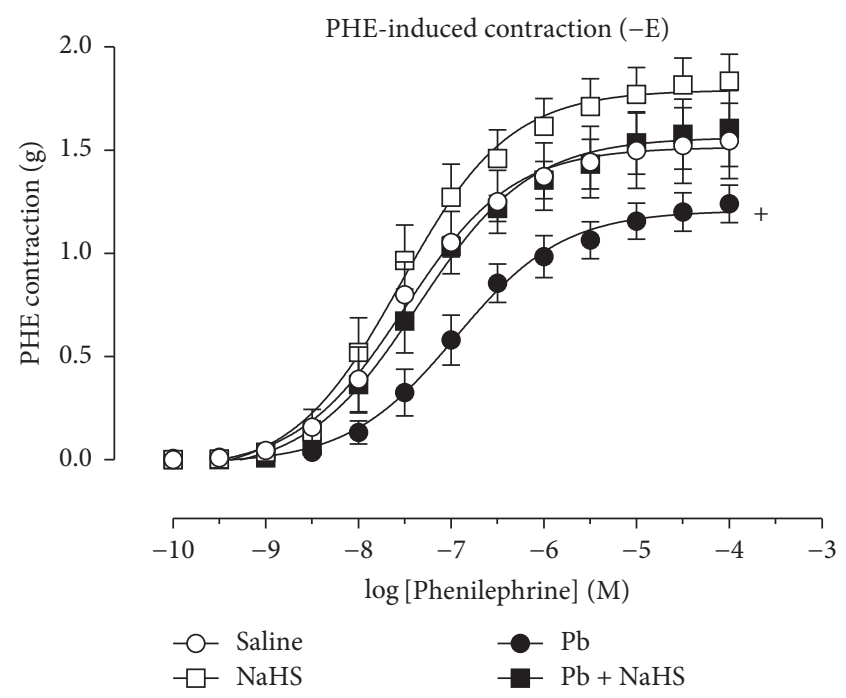

(d)
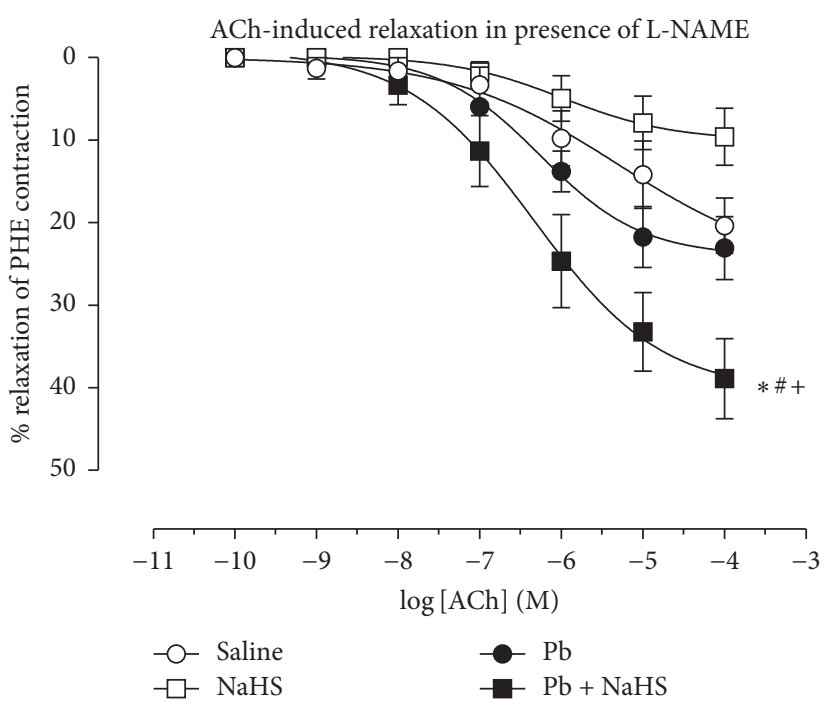

(f)

FIGURE 3: Vascular reactivity of thoracic aorta rings with $(+\mathrm{E})$ or without $(-\mathrm{E})$ endothelium from animals of four different groups: Saline (non-Pb-exposed), NaHS (non-Pb-exposed + NaHS); $\mathrm{Pb}$ (Pb-exposed), and $\mathrm{Pb}+\mathrm{NaHS}$ (Pb-exposed $+\mathrm{NaHS})$. ((a) and (b)) KCl-induced contraction. ((c) and (d)) PHE-induced contraction. (e) ACh-induced relaxation. (f) ACh-induced relaxation in presence of L-NAME. Values represent mean \pm SEM. $n=5-7 .{ }^{+} P<0.05$ versus NaHS group; ${ }^{*} P<0.05$ versus Saline group; ${ }^{\#} P<0.05$ versus $\mathrm{Pb}$ group. 
TABLE 1: KCl-induced contraction, $\mathrm{PHE}$-induced contraction, and ACh-induced relaxation in thoracic aorta of Saline, $\mathrm{NaHS}, \mathrm{Pb}$, and $\mathrm{Pb}+$ NaHS rat.

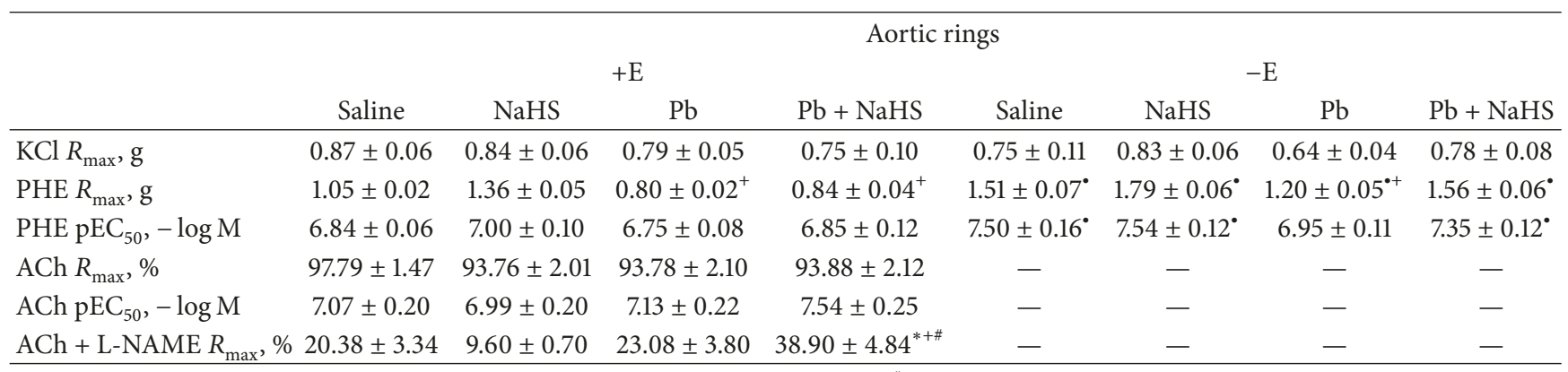

Data represents mean $\pm \operatorname{SEM}(n=5-7) .{ }^{*} P<0.05$ versus Saline. ${ }^{+} P<0.05$ versus NaHS. ${ }^{\#} P<0.05$ versus $\mathrm{Pb} .{ }^{\circ} P<0.05$ versus intact vessels $(+\mathrm{E})$ of the same animal group.

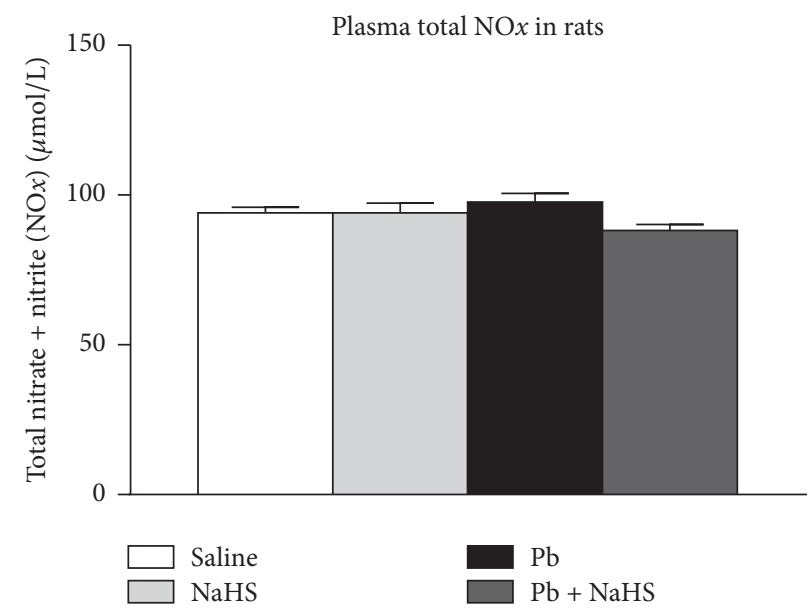

(a)

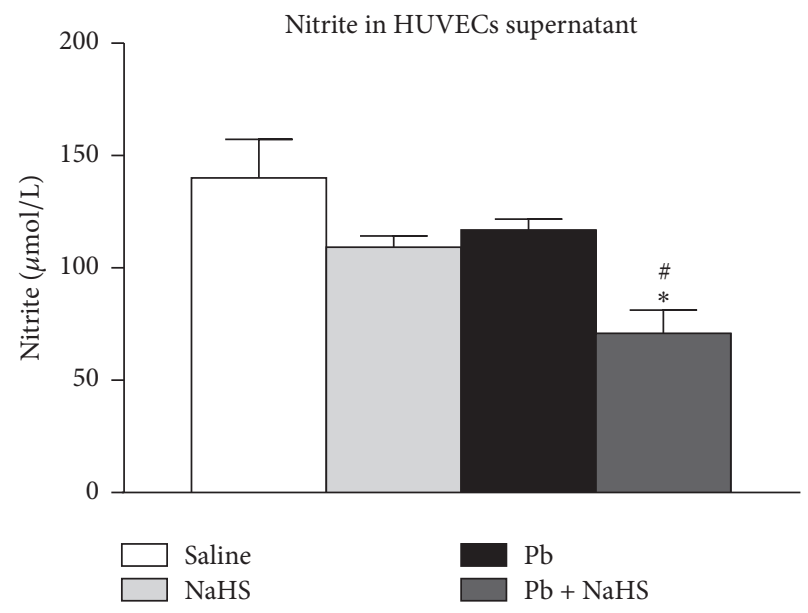

(b)

FIGURE 4: Nitric oxide availability in plasma and cell culture supernatant: Saline (non-Pb-exposed), NaHS (non- $\mathrm{Pb}$-exposed $+\mathrm{NaHS}$ ), $\mathrm{Pb}$ ( $\mathrm{Pb}$ exposed), and $\mathrm{Pb}+\mathrm{NaHS}$ (Pb-exposed + NaHS). (a) Total plasmatic NOx. (b) Nitrite levels assessed in supernatant of HUVECs incubated with $5 \%(\mathrm{v} / \mathrm{v})$ of plasma from animals of four different groups. Values represent mean \pm SEM. $n=6-12 .{ }^{*} P<0.05$ versus Saline group; ${ }^{\#} P<0.05$ versus $\mathrm{Pb}$ group.

No differences were observed in $\mathrm{pEC}_{50}$ among the four experimental groups. Denuded rings $(-\mathrm{E})$ presented higher $R_{\max }$ compared to $R_{\max }$ of respective group with intact ring $(+\mathrm{E})(P=0.0001)$ and an increase in $\mathrm{pEC}_{50}(P=0.0001)$ was also observed except in $\mathrm{Pb}$ group (Table 1). Removal of endothelium caused a higher PHE-induced contraction in NaHS versus $\mathrm{Pb}$ group $(P=0.0374$, Figure $3(\mathrm{~d})$, Table 1$)$ and no differences in $R_{\max }$ were observed among the other groups. No differences were observed in $\mathrm{pEC}_{50}$ among the experimental groups with denuded rings (Table 1).

3.4. Treatment with NaHS in Pb-Induced Hypertension Elicits an ACh-Induced Relaxation That Is Non-NO-Mediated. Relaxant responses evoked by ACh (that trigger NO release from endothelial cells) were tested in endothelium intact (+E) rings precontracted with PHE. No differences in $R_{\max }$ and $\mathrm{pEC}_{50}$ to $\mathrm{ACh}$-induced relaxation were observed among all four groups (Figure 3(e), Table 1). Blockade of nitric oxide synthase (NOS) using L-NAME caused a decrease in relaxation in Saline, $\mathrm{NaHS}$, and $\mathrm{Pb}$ groups (around 20\% of relaxation); however, maximum relaxation was greater in rings from $\mathrm{Pb}+\mathrm{NaHS}$ group compared to the other groups (around $40 \%$ of relaxation) $(P=0.004$, Figure $3(f)$, Table 1$)$.

ACh elicits a vasodilatory effect that is dependent on endothelial NO. As we observed relaxation in $\mathrm{Pb}+\mathrm{NaHS}$ group even in the presence of L-NAME, we sought to investigate the effect of NaHS treatment in NO production. Plasmatic total NO $x$ was not different between animals from experimental groups $(94.08 \pm 1.82,94.04 \pm 3.27,97.69 \pm 2.91$, and $88.18 \pm 2.03 \mu \mathrm{mol} / \mathrm{L}$ in groups Saline, $\mathrm{NaHS}, \mathrm{Pb}$, and $\mathrm{Pb}$ $+\mathrm{NaHS}$, resp., Figure 4(a)). Experiments were performed to evaluate the production of NO directly by endothelial cells; therefore, HUVECs were incubated with plasma from animals of the different groups. Surprisingly, nitrite levels were decreased in supernatant of HUVECs incubated with plasma from $\mathrm{Pb}+\mathrm{NaHS}$ group $(70.96 \pm 10.37 \mu \mathrm{mol} / \mathrm{L})$ compared with Saline $(140.10 \pm 17.14 \mu \mathrm{mol} / \mathrm{L}, P=0.0020)$ and $\mathrm{Pb}$ $(116.90 \pm 4.92 \mu \mathrm{mol} / \mathrm{L}, P=0.0261)$ groups (Figure $4(\mathrm{~b})$ ). 


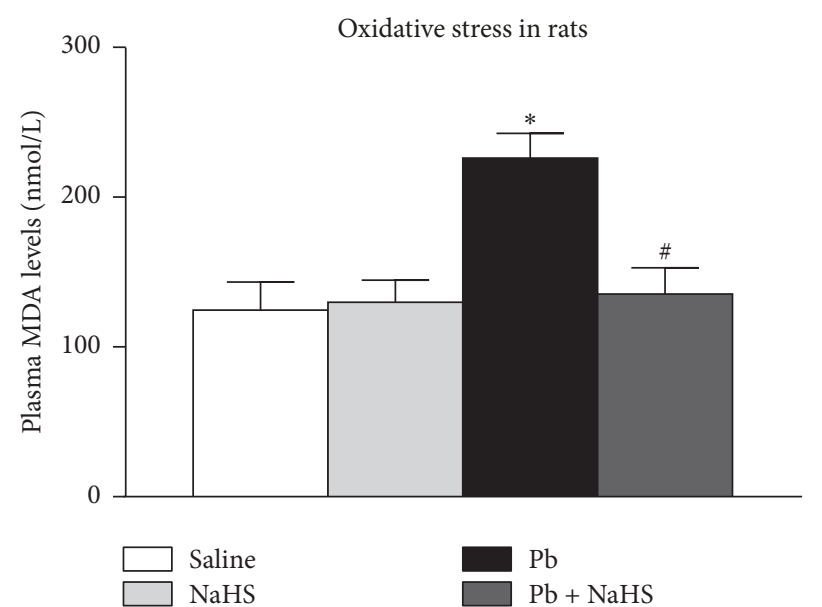

(a)

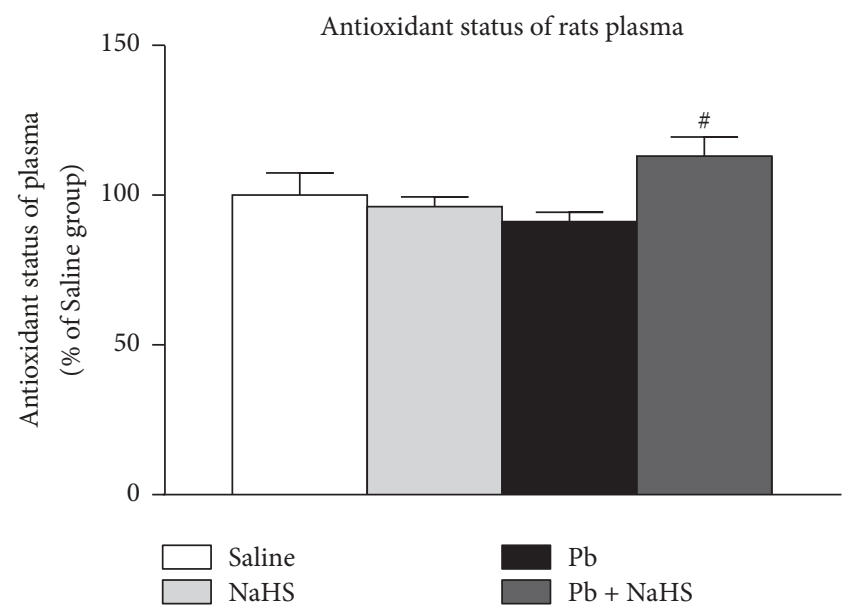

(b)

Figure 5: Oxidative stress parameters. Saline (non- $\mathrm{Pb}$-exposed), $\mathrm{NaHS}$ (non- $\mathrm{Pb}$-exposed $+\mathrm{NaHS}), \mathrm{Pb}(\mathrm{Pb}$-exposed), and $\mathrm{Pb}+\mathrm{NaHS}(\mathrm{Pb}$ exposed + NaHS). (a) MDA levels in plasma. (b) Antioxidant status of plasma as determined by MTT assay. Values represent mean \pm SEM. $n=6-12 .{ }^{*} P<0.05$ versus Saline group; ${ }^{\#} P<0.05$ versus $\mathrm{Pb}$ group.

3.5. Treatment with NaHS Reduces Oxidative Stress in $\mathrm{Pb}$ Induced Hypertension. Plasmatic MDA levels were elevated in animals exposed to $\mathrm{Pb}(226.10 \pm 16.57 \mathrm{nmol} / \mathrm{L})$ compared with animals from Saline $(P=0.0014)$ and $\operatorname{NaHS}(P=$ $0.0036)$ groups $(124.70 \pm 18.56$ and $130.00 \pm 14.62 \mathrm{nmol} / \mathrm{L}$, resp.); however, treatment of animals exposed to $\mathrm{Pb}$ with NaHS blunted the increase in plasmatic MDA (135.40 \pm $17.61 \mathrm{nmol} / \mathrm{L}$ in $\mathrm{Pb}+\mathrm{NaHS}$ group, $P=0.0025$, Figure 5(a)). Antioxidant status of plasma was not different between Saline and $\mathrm{Pb}$ groups (104.60 \pm 6.67 and $91.14 \pm 3.22 \%$, resp.) (Figure 5(b)). NaHS alone did not alter antioxidant status of plasma ( $96.20 \pm 3.25 \%$ in NaHS group); however, plasma from animals of $\mathrm{Pb}+\mathrm{NaHS}$ group showed an increase in the antioxidant status of plasma (113.10 $\pm 6.40 \%)$ compared to $\mathrm{Pb}$ group $(P=0.020$, Figure 5(b)).

\section{Discussion}

In our study, we observed an increase in diastolic and mean blood pressure in humans intoxicated with $\mathrm{Pb}$ and this was related to decreased plasmatic levels of $\mathrm{H}_{2} \mathrm{~S}$. We confirmed that acute exposition to low lead levels promoted an increase in SBP measured by tail cuff plethysmography in awaken rats. Moreover, we showed that treatment with $\mathrm{H}_{2} \mathrm{~S}$ donor, NaHS, was able to blunt the increases in SBP promoted by the acute exposition to low lead levels and that these effects of NaHS on blood pressure may be related to $\mathrm{H}_{2} \mathrm{~S}$ actions in vascular responses and $\mathrm{H}_{2} \mathrm{~S}$ antioxidant capacity.

We observed that patients intoxicated with $\mathrm{Pb}$ presented SBP similar to control patients. However, we detected an increase in diastolic and mean blood pressure in $\mathrm{Pb}$ intoxicated patients, which is in accordance with previous reports in literature showing increases in blood pressure following $\mathrm{Pb}$-intoxication in humans $[8,51-55]$. As $\mathrm{H}_{2} \mathrm{~S}$ has been shown to have several actions in cardiovascular system, we investigated the levels of $\mathrm{H}_{2} \mathrm{~S}$ in plasma from patients and found decreased plasmatic $\mathrm{H}_{2} \mathrm{~S}$ levels in patients from $\mathrm{Pb}$ intoxicated group. This result is in accordance with previous studies showing that decreased levels of $\mathrm{H}_{2} \mathrm{~S}$ are related to hypertension $[42,56-58]$ and this observation leads us to the interest in understanding the role of this gaseous mediator in $\mathrm{Pb}$-induced hypertension.

In the present study, following intoxication with lead acetate, rats developed higher SBP from exposition day five to day seven, whereas treatment with NaHS blunted this increase in blood pressure. In accordance, we detected the presence of lead in whole blood in the animals from the $\mathrm{Pb}$ group. Interestingly, we observed an approximately 2-fold decrease in whole-blood lead levels in animals treated with $\mathrm{NaHS}(\mathrm{Pb}+\mathrm{NaHS}$ group) compared with animals from $\mathrm{Pb}$ group. In fact, the reaction of $\mathrm{H}_{2} \mathrm{~S}$ with lead acetate generates lead (II) sulfide (PbS) [59].

$\mathrm{PbS}$ is a solid, dark color, almost insoluble compound. Indeed, $\mathrm{PbS}$ is insoluble and is a very stable compound at blood's $\mathrm{pH}$ [60]. Thus, the interaction of $\mathrm{H}_{2} \mathrm{~S}$ with lead acetate and consequent formation of $\mathrm{PbS}$ in animals from $\mathrm{Pb}+\mathrm{NaHS}$ group may explain the lower whole-blood lead levels detected in our study. Accordingly, previous studies in rats fed with different compounds of lead showed that animals receiving $\mathrm{PbS}$ presented diminished whole-blood lead levels when compared with rats receiving different $\mathrm{Pb}$-based compounds, such as lead acetate and lead oxide [60].

One may consider that the nonobserved increase in SBP in animals from $\mathrm{Pb}+\mathrm{NaHS}$ group may be due to the lower whole-blood $\mathrm{Pb}$ levels. Although the diminished $\mathrm{Pb}$ levels in $\mathrm{Pb}+\mathrm{NaHS}$ group may partially contribute to the attenuation in the increases of SBP, these animals presented whole-blood $\mathrm{Pb}$ levels of $12.96 \pm 1.81 \mu \mathrm{g} / \mathrm{dL}$. In addition, it has been shown that whole-blood lead levels below or very close to those found in our study are related to increases in blood pressure. Previous studies from our group showed that animals with $9 \pm 1 \mu \mathrm{g} / \mathrm{dL}$ [9] and $11.5 \pm 1.2 \mu \mathrm{g} / \mathrm{dL}$ [13] presented an increase 
in SBP and other groups also reported an increase in blood pressure of rats with whole-blood lead levels of $12 \pm 1.34 \mu \mathrm{g} / \mathrm{dL}$ [12] and $9.98 \pm 1.70 \mu \mathrm{g} / \mathrm{dL}$ [18]. Therefore, a mechanistic action of $\mathrm{H}_{2} \mathrm{~S}$ must be involved in the decreases of blood pressure promoted by $\mathrm{NaHS}$ in $\mathrm{Pb}$-induced hypertension.

Interestingly, followed by the reductions in whole-blood lead levels, $\mathrm{H}_{2} \mathrm{~S}$ in plasma was increased in $\mathrm{Pb}+\mathrm{NaHS}$ group. As $\mathrm{H}_{2} \mathrm{~S}$ and lead acetate may interact and the $\mathrm{PbS}$ generated is expected to be eliminated from the organism, one would inquire that $\mathrm{H}_{2} \mathrm{~S}$ should be lower in $\mathrm{Pb}+\mathrm{NaHS}$ group. However, it has been demonstrated that NaHS may induce the formation of polysulfides $\left(\mathrm{H}_{2} \mathrm{~S}_{n}, n>1\right)$ [61] and that either endogenous or exogenous $\mathrm{H}_{2} \mathrm{~S}$ may generate polysulfides through its interaction with ROS, such as superoxide anion [62-64].

Lead-intoxicated animals ( $\mathrm{Pb}$ group) presented increases in oxidative stress, which was reduced in $\mathrm{Pb}+\mathrm{NaHS}$ group. Reductions in oxidative stress in animals of $\mathrm{Pb}+\mathrm{NaHS}$ group may be related to the reaction of exogenous $\mathrm{H}_{2} \mathrm{~S}$ with ROS. Also, recent studies suggest that effects initially described for $\mathrm{H}_{2} \mathrm{~S}$ may rely (partially or totally) on polysulfides [65]; therefore, polysulfides generated in $\mathrm{Pb}+\mathrm{NaHS}$ animals may be responsible for the beneficial effects observed in our study. Importantly, the method used in our study to measure $\mathrm{H}_{2} \mathrm{~S}$, the methyl blue formation method, may not distinguish between $\mathrm{H}_{2} \mathrm{~S}$ itself and polysulfide compounds. Thus, increased levels of $\mathrm{H}_{2} \mathrm{~S}$ shown in Figure 2(c) may represent polysulfides formation.

In order to understand the vascular effects promoted by lead intoxication and the NaHS treatment, vascular reactivity experiments have been performed. No differences were observed in $\mathrm{KCl}$-induced contraction between groups with $(+\mathrm{E})$ or without $(-\mathrm{E})$ endothelium. However, greater contraction to $\mathrm{PHE}$ was reached by aortic rings from animals treated with NaHS when compared to both groups receiving $\mathrm{Pb}(\mathrm{Pb}$ and $\mathrm{Pb}+\mathrm{NaHS}$ group). While the findings on $\mathrm{KCl}-$ induced contraction do not point to increased vascular $\mathrm{Ca}^{2+}$ influx through voltage-gated $\mathrm{Ca}^{2+}$ channels $[44,66], \mathrm{PHE}$ may also activate $\mathrm{Ca}^{2+}$ influx through receptor and storeoperated $\mathrm{Ca}^{2+}$ channels $[44,66]$; thus a greater influx of $\mathrm{Ca}^{2+}$ induced by changes promoted by the NaHS treatment must be considered. Also, the increases in contractile responses in NaHS group could be explained by changes in endotheliumdependent relaxation pathways. It was demonstrated that, in low doses, NaHS elicited a vasoconstriction in rats' aortas and mixing NaHS with NO donors inhibited the vasorelaxant effect of NO, both in vitro and in vivo [67]. Since the procontractile effects of $\mathrm{H}_{2} \mathrm{~S}$ were prevented by removing the endothelium or inhibition of eNOS, it has been suggested that $\mathrm{H}_{2} \mathrm{~S}$ acted to remove the basal vasorelaxatory influence of $\mathrm{NO}$ to produce contraction. Further, these authors showed that $\mathrm{H}_{2} \mathrm{~S}$ and NO may interact to generate an inactive nitrosothiol product [68].

Removal of endothelium promoted increases in $R_{\max }$ and $\mathrm{pEC}_{50}(P<0.05$, Table 1$)$; however, no differences were observed in $\mathrm{pEC}_{50}$ between intact and denuded rings from $\mathrm{Pb}$ group $(P>0.05$, Table 1$)$. This indicates that presence of endothelium and, consequently, the protective factors released by endothelial cells were not able to counterbalance the vasoconstrictor effect of $\mathrm{PHE}$ in $\mathrm{Pb}$ group, which may suggest the installation of some endothelial damage after seven days of exposure to low lead levels.

Rings from $\mathrm{Pb}$ and $\mathrm{Pb}+\mathrm{NaHS}$ groups presented the lower mean values of contraction, and although these values were not significantly different from Saline group, they reached statistical significance compared to NaHS group. Interestingly, $\mathrm{Pb}+\mathrm{NaHS}$ aortic rings presented decreased $R_{\max }$ when compared to NaHS group only in rings with intact endothelium, whereas removal of endothelial cells abolished this diminished contraction. Since removal of endothelium abolished this difference in contraction between $\mathrm{Pb}+\mathrm{NaHS}$ group and NaHS group, we suggest that NaHS treatment may exert a protective effect that is dependent on endothelium only in the presence of hypertension. Vascular effects of $\mathrm{H}_{2} \mathrm{~S}$ are not fully comprehended and both contraction $[58,69,70]$ and relaxation $[58,67,71-73]$ have been shown to occur as an effect of $\mathrm{H}_{2} \mathrm{~S}$. It has been shown before that removal of endothelium [73] or inhibition of NO production [74] reduced relaxant responses to $\mathrm{H}_{2} \mathrm{~S}$; this supports our findings in which removal of endothelium abolished this protective effect induced by NaHS treatment in hypertensive animals.

Although relaxation induced by interactions of $\mathrm{H}_{2} \mathrm{~S}$ with NO has been described previously [31, 71, 75, 76], in our hands, following $\mathrm{Pb}$ exposition and $\mathrm{NaHS}$ treatment, no differences in endothelial NO-dependent relaxation promoted by $\mathrm{ACh}$ were observed. However, when relaxation was triggered by ACh in the presence of NOS inhibitor LNAME, a relaxation around $40 \%$ was reached in aortic rings from animals of $\mathrm{Pb}+\mathrm{NaHS}$ group. Previous studies showed that $\mathrm{H}_{2} \mathrm{~S}$ may increase expression and activity of eNOS $[77,78]$, thus producing more $\mathrm{NO}$, and this excessive $\mathrm{NO}$ could be responsible for relaxation observed in the presence of L-NAME. However, we did not observe any alteration in plasmatic total NOx from animals of different groups; and interesting data was observed with nitrite measured in HUVECs' culture supernatant. Following incubation with plasma from different animal groups, we observed that cells treated with plasma from $\mathrm{Pb}+\mathrm{NaHS}$ group presented lower nitrite levels compared to cells treated with plasma from Saline and $\mathrm{Pb}$ groups. These results support our observation in vascular reactivity experiments where relaxation in $\mathrm{Pb}$ + NaHS group may be triggered in an NO-independent way. Since NO-independent relaxation was reached in vessels from $\mathrm{Pb}+\mathrm{NaHS}$ group and not in vessels from animals treated only with NaHS, we speculate that only in presence of hypertension, which may trigger several defensive mechanisms in the organism, does $\mathrm{H}_{2} \mathrm{~S}$ promote relaxation independently from $\mathrm{NO}$ presence and strongly recommend future studies in the field.

As interaction with $\mathrm{NO}$ seems not to be involved in the beneficial effects of $\mathrm{H}_{2} \mathrm{~S}$ in $\mathrm{Pb}$-induced hypertension, we performed additional experiments to better understand the role of $\mathrm{H}_{2} \mathrm{~S}$ during $\mathrm{Pb}$-induced hypertension. Increases in oxidative stress contribute to hypertension and have been pointed as a possible mechanism underlying $\mathrm{Pb}$-induced hypertension $[18,19]$, while $\mathrm{H}_{2} \mathrm{~S}$ has been shown to exert antioxidant activity $[79,80]$. Therefore, we sought to investigate the effects of $\mathrm{H}_{2} \mathrm{~S}$ in oxidative stress in $\mathrm{Pb}$-induced 
hypertension. We found that plasma from $\mathrm{Pb}$ group presented higher levels of MDA. As MDA is a metabolite of lipid peroxidation [81], increased MDA levels in these animals indicate higher levels of oxidative stress. In our hands, treatment of hypertensive animals with $\mathrm{NaHS}(\mathrm{Pb}+\mathrm{NaHS}$ group) blunted the increase in oxidative stress; moreover, decreased MDA levels were followed by an increase in the antioxidant status of plasma in $\mathrm{Pb}+\mathrm{NaHS}$ group, as measured by the MTT assay [50]. Accordingly, previous studies have shown the role of $\mathrm{H}_{2} \mathrm{~S}$ in reduction of oxidative stress and increases in antioxidant capacity [36, 82-84]. These results suggest that beneficial effects of $\mathrm{H}_{2} \mathrm{~S}$ in $\mathrm{Pb}$-induced hypertension may be related to $\mathrm{H}_{2} \mathrm{~S}$ antioxidant capacity and reductions in oxidative stress.

In conclusion, we showed that increases in diastolic and mean blood pressure in human patients intoxicated with $\mathrm{Pb}$ may be related to decreased $\mathrm{H}_{2} \mathrm{~S}$ plasmatic levels. Treatment with $\mathrm{H}_{2} \mathrm{~S}$ donor blunted increases in SBP in rats and this beneficial effect of NaHS may not be related to NO. Importantly, we showed that treatment with NaHS in hypertensive animals led to vascular relaxation induced by ACh which is non-NO-mediated. Therefore, the antioxidant capacity of $\mathrm{H}_{2} \mathrm{~S}$ may also be involved in reductions in blood pressure in $\mathrm{Pb}$-induced hypertension.

\section{Conflicts of Interest}

The authors declare that there are no conflicts of interest.

\section{Acknowledgments}

This study was supported by funding from Fundação de Amparo a Pesquisa do Estado de São Paulo (FAPESP, Brazil) and Coordenação de Aperfeiçoamento de Pessoal de Nível Superior (CAPES, Brazil).

\section{References}

[1] N. Healey, "Lead toxicity, vulnerable subpopulations and emergency preparedness," Radiation Protection Dosimetry, vol. 134, no. 3-4, pp. 143-151, 2009.

[2] O. Awodele, T. D. Popoola, K. C. Amadi, H. A. B. Coker, and A. Akintonwa, "Traditional medicinal plants in NigeriaRemedies or risks," Journal of Ethnopharmacology, vol. 150, no. 2, pp. 614-618, 2013.

[3] R. Renner, "Out of plumb: when water treatment causes lead contamination," Environmental Health Perspectives, vol. 117, no. 12, pp. A543-A547, 2009.

[4] P. Álvarez-Lloret, C. M. Lee, M. I. Conti, A. R. Terrizzi, S. González-López, and M. P. Martínez, "Effects of chronic lead exposure on bone mineral properties in femurs of growing rats," Toxicology, vol. 377, pp. 64-72, 2017.

[5] C. M. Lee, A. R. Terrizzi, C. Bozzini, A. E. Piñeiro, M. I. Conti, and M. P. Martínez, "Chronic lead poisoning magnifies bone detrimental effects in an ovariectomized rat model of postmenopausal osteoporosis," Experimental and Toxicologic Pathology, vol. 68, no. 1, pp. 47-53, 2016.

[6] N. Newman, "Investigation of childhood lead poisoning from parental take-home exposure from an electronic scrap recycling
facility-Ohio, 2012," MMWR Morbidity and Mortality Weekly Report, vol. 64, no. 27, pp. 743-745, 2015.

[7] M. G. Flores-Montoya and C. Sobin, "Early chronic lead exposure reduces exploratory activity in young C57BL/6J mice," Journal of Applied Toxicology, vol. 35, no. 7, pp. 759-765, 2015.

[8] M. J. Kosnett, R. P. Wedeen, S. J. Rothenberg et al., "Recommendations for medical management of adult lead exposure," Environmental Health Perspectives, vol. 115, no. 3, pp. 463-471, 2006.

[9] R. A. Nascimento, G. Mendes, J. S. Possomato-Vieira et al., "Metalloproteinase inhibition protects against reductions in circulating adrenomedullin during lead-induced acute hypertension," Basic \& Clinical Pharmacology \& Toxicology, vol. 116, no. 6, pp. 508-515, 2015.

[10] B. S. Glenn, W. F. Stewart, J. M. Links, A. C. Todd, and B. S. Schwartz, "The longitudinal association of lead with blood pressure," Epidemiology, vol. 14, no. 1, pp. 30-36, 2003.

[11] W. A. Alarcon, E. State Adult Blood Lead, and I. Surveillance Program, "Elevated blood lead levels among employed adults-United States, 1994-2013," MMWR Morbidity and Mortality Weekly Report, vol. 63, no. 55, pp. 59-65, 2016.

[12] E. A. Silveira, F. D. M. Siman, T. De Oliveira Faria et al., "Lowdose chronic lead exposure increases systolic arterial pressure and vascular reactivity of rat aortas," Free Radical Biology \& Medicine, vol. 67, pp. 366-376, 2014.

[13] V. H. Gonçalves-Rizzi, R. A. Nascimento, J. S. Possomato-Vieira, and C. A. Dias-Junior, "Sodium nitrite prevents both reductions in circulating nitric oxide and hypertension in 7-day leadtreated rats," Basic \& Clinical Pharmacology \& Toxicology, vol. 118, no. 3, pp. 225-230, 2016.

[14] E. Gould, "Childhood lead poisoning: conservative estimates of the social and economic benefits of lead hazard control," Environmental Health Perspectives, vol. 117, no. 7, pp. 1162-1167, 2009.

[15] M. R. Simões, S. C. Preti, B. F. Azevedo et al., "Low-level chronic lead exposure impairs neural control of blood pressure and heart rate in rats," Cardiovascular Toxicology, vol. 17, no. 2, pp. 190-199, 2017.

[16] E. Rizzi, M. M. Castro, K. Fernandes et al., "Evidence of early involvement of matrix metalloproteinase-2 in lead-induced hypertension," Archives of Toxicology, vol. 83, no. 5, pp. 439-449, 2009.

[17] N. Dursun, C. Arifoglu, C. Süer, and L. Keskinol, "Blood pressure relationship to nitric oxide, lipid peroxidation, renal function, and renal blood flow in rats exposed to low lead levels," Biological Trace Element Research, vol. 104, no. 2, pp. 141-149, 2005.

[18] J. Fiorim, R. F. Ribeiro Jr., E. A. Silveira et al., "Low-level lead exposure increases systolic arterial pressure and endotheliumderived vasodilator factors in rat aortas," PLOS ONE, vol. 6, no. 2, Article ID e17117, 2011.

[19] E. Caylak, M. Aytekin, and I. Halifeoglu, "Antioxidant effects of methionine, $\alpha$-lipoic acid, $\mathrm{N}$-acetylcysteine and homocysteine on lead-induced oxidative stress to erythrocytes in rats," Experimental and Toxicologic Pathology, vol. 60, no. 4-5, pp. 289-294, 2008.

[20] X. Zhang and J.-S. Bian, "Hydrogen sulfide: a neuromodulator and neuroprotectant in the central nervous system," ACS Chemical Neuroscience, vol. 5, no. 10, pp. 876-883, 2014.

[21] D. Feliers, H. J. Lee, and B. S. Kasinath, "Hydrogen sulfide in renal physiology and disease," Antioxidants \& Redox Signaling, vol. 25, no. 13, pp. 720-731, 2016. 
[22] C. Szabo, "Hydrogen sulfide, an enhancer of vascular nitric oxide signaling: mechanisms and implications," American Journal of Physiology-Cell Physiology, vol. 312, no. 1, pp. C3-C15, 2017.

[23] S. K. Jain, R. Bull, J. L. Rains et al., "Low levels of hydrogen sulfide in the blood of diabetes patients and streptozotocintreated rats causes vascular inflammation?" Antioxidants \& Redox Signaling, vol. 12, no. 11, pp. 1333-1337, 2010.

[24] X. Cao and J.-S. Bian, "The role of hydrogen sulfide in renal system," Frontiers in Pharmacology, vol. 7, Article ID 385, 2016.

[25] N. L. Kanagy, C. Szabo, and A. Papapetropoulos, "Vascular biology of hydrogen sulfide," American Journal of PhysiologyCell Physiology, vol. 312, no. 5, pp. C537-C549, 2017.

[26] J. L. Wallace and R. Wang, "Hydrogen sulfide-based therapeutics: exploiting a unique but ubiquitous gasotransmitter," Nature Reviews Drug Discovery, vol. 14, no. 5, pp. 329-345, 2015.

[27] N. Shibuya, M. Tanaka, M. Yoshida et al., "3-Mercaptopyruvate sulfurtransferase produces hydrogen sulfide and bound sulfane sulfur in the brain," Antioxidants \& Redox Signaling, vol. 11, no. 4, pp. 703-714, 2009.

[28] H. Kimura, "The physiological role of hydrogen sulfide and beyond," Nitric Oxide: Biology and Chemistry, vol. 41, pp. 4-10, 2014.

[29] K. Abe and H. Kimura, "The possible role of hydrogen sulfide as an endogenous neuromodulator," The Journal of Neuroscience, vol. 16, no. 3, pp. 1066-1071, 1996.

[30] M. Caprnda, T. Qaradakhi, J. L. Hart et al., "H2S causes contraction and relaxation of major arteries of the rabbit," Biomedicine \& Pharmacotherapy, vol. 89, pp. 56-60, 2017.

[31] S. Materazzi, G. Zagli, R. Nassini et al., "Vasodilator activity of hydrogen sulfide (H2S) in human mesenteric arteries," Microvascular Research, vol. 109, pp. 38-44, 2017.

[32] C. Hou, M. Wang, C. Sun et al., "Protective effects of hydrogen sulfide in the ageing kidney," Oxidative Medicine and Cellular Longevity, vol. 2016, pp. 1-13, 2016.

[33] S. G. Spassov, R. Donus, P. M. Ihle, H. Engelstaedter, A. Hoetzel, and S. Faller, "Hydrogen sulfide prevents formation of reactive oxygen species through PI3K/Akt signaling \& limits ventilatorinduced lung injury," Oxidative Medicine and Cellular Longevity, vol. 2017, Article ID 3715037, 2017.

[34] X. Sun, W. Wang, J. Dai et al., "A long-term and slowreleasing hydrogen sulfide donor protects against myocardial ischemia/reperfusion injury," Scientific Reports, vol. 7, no. 1, Article ID 3541, 2017.

[35] W. Wu, C.-L. Hou, X.-P. Mu et al., "H2S Donor NaHS Changes the Production of Endogenous H2S and NO in D-GalactoseInduced Accelerated Ageing," Oxidative Medicine and Cellular Longevity, vol. 2017, Article ID 5707830, 14 pages, 2017.

[36] M. Shao, C. Zhuo, R. Jiang et al., "Protective effect of hydrogen sulphide against myocardial hypertrophy in mice," Oncotarget, vol. 8, no. 14, pp. 22344-22352, 2017.

[37] S. Muzaffar, N. Shukla, M. Bond et al., "Exogenous hydrogen sulfide inhibits superoxide formation, NOX-1 expression and Racl activity in human vascular smooth muscle cells," Journal of Vascular Research, vol. 45, no. 6, pp. 521-528, 2008.

[38] M. R. Al-Magableh, B. K. Kemp-Harper, H. H. Ng, A. A. Miller, and J. L. Hart, "Hydrogen sulfide protects endothelial nitric oxide function under conditions of acute oxidative stress in vitro," Naunyn-Schmiedeberg's Archives of Pharmacology, vol. 387, no. 1, pp. 67-74, 2014.

[39] A. Ford, M. Al-Magableh, T. A. Gaspari, and J. L. Hart, "Chronic NaHS treatment is vasoprotective in high-fat-fed $\mathrm{ApoE}^{-/-}$ mice," International Journal of Vascular Medicine, vol. 2013, Article ID 915983, 8 pages, 2013.

[40] M. R. Al-Magableh, B. K. Kemp-Harper, and J. L. Hart, "Hydrogen sulfide treatment reduces blood pressure and oxidative stress in angiotensin II-induced hypertensive mice," Hypertension Research, vol. 38, no. 1, pp. 13-20, 2015.

[41] K. Suzuki, G. Olah, K. Modis et al., "Hydrogen sulfide replacement therapy protects the vascular endothelium in hyperglycemia by preserving mitochondrial function," in Proceedings of the National Acadamy of Sciences of the United States of America, vol. 108, 33, pp. 13829-13834, 2011.

[42] K. Q. Wang, S. Ahmad, M. Cai et al., "Dysregulation of hydrogen sulfide producing enzyme cystathionine $\gamma$-lyase contributes to maternal hypertension and placental abnormalities in preeclampsia," Circulation, vol. 127, no. 25, pp. 2514-2522, 2013.

[43] Y. Zhuo, P.-F. Chen, A.-Z. Zhang, H. Zhong, C.-Q. Chen, and Y.Z. Zhu, "Cardioprotective effect of hydrogen sulfide in ischemic reperfusion experimental rats and its influence on expression of survivin gene," Biological \& Pharmaceutical Bulletin, vol. 32, no. 8, pp. 1406-1410, 2009.

[44] M. Zhu, Z. Ren, J. S. Possomato-Vieira, and R. A. Khalil, "Restoring placental growth factor-soluble fms-like tyrosine kinase-1 balance reverses vascular hyper-reactivity and hypertension in pregnancy," American Journal of Physiology-Regulatory, Integrative and Comparative Physiology, vol. 311, no. 3, pp. R505-R521, 2016.

[45] R. F. F. De Baptista, A. B. Chies, E. F. De Taipeiro, and S. Cordellini, "Endothelial at ${ }_{1}$ and $\mathrm{at}_{2}$ pathways in aortic responses to angiotensin II after stress and ethanol consumption in rats," Stress, vol. 17, no. 6, pp. 512-519, 2014.

[46] T. Mosmann, "Rapid colorimetric assay for cellular growth and survival: application to proliferation and cytotoxicity assays," Journal of Immunological Methods, vol. 65, no. 1-2, pp. 55-63, 1983.

[47] L. Rocha-Penha, M. Caldeira-Dias, J. E. Tanus-Santos, R. De Carvalho Cavalli, and V. C. Sandrim, "Myeloperoxidase in hypertensive disorders of pregnancy and its relation with nitric oxide," Hypertension, vol. 69, no. 6, pp. 1173-1180, 2017.

[48] K. M. Miranda, M. G. Espey, and D. A. Wink, "A rapid, simple spectrophotometric method for simultaneous detection of nitrate and nitrite," Nitric Oxide: Biology and Chemistry, vol. 5, no. 1, pp. 62-71, 2001.

[49] L. L. Périco, S. C. Heredia-Vieira, F. P. Beserra et al., "Does the gastroprotective action of a medicinal plant ensure healing effects? An integrative study of the biological effects of Serjania marginata Casar. (Sapindaceae) in rats," Journal of Ethnopharmacology, vol. 172, pp. 312-324, 2015.

[50] L. O. Medina, C. A. Veloso, É. de Abreu Borges et al., "Determination of the antioxidant status of plasma from type 2 diabetic patients," Diabetes Research and Clinical Practice, vol. 77, no. 2, pp. 193-197, 2007.

[51] A. C. B. D. A. Lopes, E. K. Silbergeld, A. Navas-Acien et al., "Association between blood lead and blood pressure: a population-based study in Brazilian adults," Environmental Health: A Global Access Science Source, vol. 16, no. 1, Article ID 27, 2017.

[52] S. Vupputuri, J. He, P. Muntner, L. A. Bazzano, P. K. Whelton, and V. Batuman, "Blood lead level is associated with elevated blood pressure in blacks," Hypertension, vol. 41, no. 3 I, pp. 463468, 2003. 
[53] Y. Cheng, J. Schwartz, D. Sparrow, A. Aro, S. T. Weiss, and H. $\mathrm{Hu}$, "Bone lead and blood lead levels in relation to baseline blood pressure and the prospective development of hypertension. The normative aging study," American Journal of Epidemiology, vol. 153, no. 2, pp. 164-171, 2001.

[54] F. Barbosa Jr., R. F. Gerlach, and J. E. Tanus-Santos, "Matrix metalloproteinase-9 activity in plasma correlates with plasma and whole blood lead concentrations," Basic \& Clinical Pharmacology \& Toxicology, vol. 98, no. 6, pp. 559-564, 2006.

[55] S. K. Shakir, A. Azizullah, W. Murad et al., "Toxic Metal Pollution in Pakistan and Its Possible Risks to Public Health," in Reviews of Environmental Contamination and Toxicology, vol. 242, pp. 1-60, Springer International Publishing, Cham, Germany, 2017.

[56] H. van Goor, J. C. van den Born, J. Hillebrands, and J. A. Joles, "Hydrogen sulfide in hypertension," Current Opinion in Nephrology and Hypertension, vol. 25, no. 2, pp. 107-113, 2016.

[57] J. L. Greaney, J. L. Kutz, S. W. Shank, S. Jandu, L. Santhanam, and L. M. Alexander, "Impaired hydrogen sulfide-mediated vasodilation contributes to microvascular endothelial dysfunction in hypertensive adults," Hypertension, vol. 69, no. 5, pp. 902-909, 2017.

[58] S. Cacanyiova, A. Berenyiova, F. Kristek, M. Drobna, K. Ondrias, and M. Grman, "The adaptive role of nitric oxide and hydrogen Sulphide in vasoactive responses of thoracic aorta is triggered already in young spontaneously hypertensive rats," Journal of Physiology and Pharmacology, vol. 67, no. 4, pp. 501512, 2016.

[59] Y. Zhang and J. H. Weiner, "A simple semi-quantitative in vivo method using $\mathrm{H}_{2} \mathrm{~S}$ detection to monitor sulfide metabolizing enzymes," BioTechniques, vol. 57, no. 4, pp. 208-210, 2014.

[60] M. P. Dieter, H. B. Matthews, R. A. Jeffcoat, and R. F. Moseman, "Comparison of lead bioavailability in $\mathrm{f} 344$ rats fed lead acetate, lead oxide, lead sulfide, or lead ore concentrate from skagway, alaska," Journal of Toxicology and Environmental Health, vol. 39, no. 1, pp. 79-93, 1993.

[61] R. Greiner, Z. Pálinkás, K. Bäsell et al., "Polysulfides link $\mathrm{H}_{2} \mathrm{~S}$ to protein thiol oxidation," Antioxidants \& Redox Signaling, vol. 19, no. 15, pp. 1749-1765, 2013.

[62] Y. Huang, F. Yu, J. Wang, and L. Chen, "Near-infrared fluorescence probe for in situ detection of superoxide anion and hydrogen polysulfides in mitochondrial oxidative stress," Analytical Chemistry, vol. 88, no. 7, pp. 4122-4129, 2016.

[63] P. Nagy and C. C. Winterbourn, "Rapid reaction of hydrogen sulfide with the neutrophil oxidant hypochlorous acid to generate polysulfides," Chemical Research in Toxicology, vol. 23, no. 10, pp. 1541-1543, 2010.

[64] P. Nagy, Z. Pálinkás, A. Nagy, B. Budai, I. Tóth, and A. Vasas, "Chemical aspects of hydrogen sulfide measurements in physiological samples," Biochimica et Biophysica Acta, vol. 1840, no. 2, pp. 876-891, 2014.

[65] K. R. Olson, " $\mathrm{H}_{2} \mathrm{~S}$ and polysulfide metabolism: conventional and unconventional pathways," Biochemical Pharmacology, vol. 149, pp. 77-90, 2018.

[66] J. G. Murphy, J. N. Herrington, J. P. Granger, and R. A. Khalil, "Enhanced $\left[\mathrm{Ca}^{2+}\right] \mathrm{i}$ in renal arterial smooth muscle cells of pregnant rats with reduced uterine perfusion pressure," American Journal of Physiology-Heart and Circulatory Physiology, vol. 284, no. 1, pp. H393-H403, 2003.

[67] M. Y. Ali, C. Y. Ping, Y. Y. P. Mok et al., "Regulation of vascular nitric oxide in vitro and in vivo; a new role for endogenous hydrogen sulphide?" British Journal of Pharmacology, vol. 149, no. 6, pp. 625-634, 2006.

[68] M. Whiteman, L. Li, I. Kostetski et al., "Evidence for the formation of a novel nitrosothiol from the gaseous mediators nitric oxide and hydrogen sulphide," Biochemical and Biophysical Research Communications, vol. 343, no. 1, pp. 303-310, 2006.

[69] Y.-H. Liu and J.-S. Bian, "Bicarbonate-dependent effect of hydrogen sulfide on vascular contractility in rat aortic rings," American Journal of Physiology-Cell Physiology, vol. 299, no. 4, pp. C866-C872, 2010.

[70] J. L. Jia, Y.-H. Liu, E. S. W. Khin, and J.-S. Bian, "Vasoconstrictive effect of hydrogen sulfide involves downregulation of cAMP in vascular smooth muscle cells," American Journal of PhysiologyCell Physiology, vol. 295, no. 5, pp. C1261-C1270, 2008.

[71] R. Hosoki, N. Matsuki, and H. Kimura, "The possible role of hydrogen sulfide as an endogenous smooth muscle relaxant in synergy with nitric oxide," Biochemical and Biophysical Research Communications, vol. 237, no. 3, pp. 527-531, 1997.

[72] L. Xiao, J.-H. Dong, S. Jin et al., "Hydrogen sulfide improves endothelial dysfunction via downregulating BMP4/COX-2 pathway in rats with hypertension," Oxidative Medicine and Cellular Longevity, vol. 2016, Article ID 8128957, 10 pages, 2016.

[73] W. Zhao, J. Zhang, Y. Lu, and R. Wang, “The vasorelaxant effect of $\mathrm{H}_{2} \mathrm{~S}$ as a novel endogenous gaseous $\mathrm{K}_{\text {ATP }}$ channel opener," EMBO Journal, vol. 20, no. 21, pp. 6008-6016, 2001.

[74] W. Zhao and R. Wang, " $\mathrm{H}_{2} \mathrm{~S}$-induced vasorelaxation and underlying cellular and molecular mechanisms," American Journal of Physiology-Heart and Circulatory Physiology, vol. 283, no. 2, pp. H474-H480, 2002.

[75] F. Aydinoglu, F. T. Dalkir, H. O. Demirbag, and N. Ogulener, "The interaction of L-cysteine/ $\mathrm{H}_{2} \mathrm{~S}$ pathway and muscarinic acetylcholine receptors (mAChRs) in mouse corpus cavernosum," Nitric Oxide: Biology and Chemistry, vol. 70, pp. 51-58, 2017.

[76] Y. F. Wang, P. Mainali, C. S. Tang et al., "Effects of nitric oxide and hydrogen sulfide on the relaxation of pulmonary arteries in rats," Chinese Medical Journal, vol. 121, no. 5, pp. 420-423, 2008.

[77] P.-H. Chen, Y.-S. Fu, Y.-M. Wang, K.-H. Yang, D. L. Wang, and B. Huang, "Hydrogen sulfide increases nitric oxide production and subsequent S-nitrosylation in endothelial cells," The Scientific World Journal, vol. 2014, Article ID 480387, 8 pages, 2014.

[78] B. Huang, C.-T. Chen, C.-S. Chen, Y.-M. Wang, H.-J. Hsieh, and D. L. Wang, "Laminar shear flow increases hydrogen sulfide and activates a nitric oxide producing signaling cascade in endothelial cells," Biochemical and Biophysical Research Communications, vol. 464, no. 4, pp. 1254-1259, 2015.

[79] X. Zhou, L. Zhao, J. Mao, J. Huang, and J. Chen, "Antioxidant effects of hydrogen sulfide on left ventricular remodeling in smoking rats are mediated via PI3K/Akt-dependent activation of Nrf2," Toxicological Sciences, vol. 144, no. 1, pp. 197-203, 2015.

[80] P. Aghagolzadeh, R. Radpour, M. Bachtler et al., "Hydrogen sulfide attenuates calcification of vascular smooth muscle cells via KEAP1/NRF2/NQO1 activation," Atherosclerosis, vol. 265, pp. 78-86, 2017.

[81] H. Ohkawa, N. Ohishi, and K. Yagi, "Assay for lipid peroxides in animal tissues by thiobarbituric acid reaction," Analytical Biochemistry, vol. 95, no. 2, pp. 351-358, 1979.

[82] X. Chen, X. Zhao, H. Cai et al., "The role of sodium hydrosulfide in attenuating the aging process via PI3K/AKT and CaMKK $\beta /$ AMPK pathways," Redox Biology, vol. 12, pp. 9871003, 2017. 
[83] R. Yang, Q. Jia, X.-F. Liu, Y.-Y. Wang, and S.-F. Ma, "Effects of hydrogen sulfide on inducible nitric oxide synthase activity and expression of cardiomyocytes in diabetic rats," Molecular Medicine Reports, vol. 16, no. 4, pp. 5277-5284, 2017.

[84] L. Xie, S. Yu, K. Yang, C. Li, and Y. Liang, "Hydrogen sulfide inhibits autophagic neuronal cell death by reducing oxidative stress in spinal cord ischemia reperfusion injury," Oxidative Medicine and Cellular Longevity, vol. 2017, Article ID 8640284, 15 pages, 2017. 

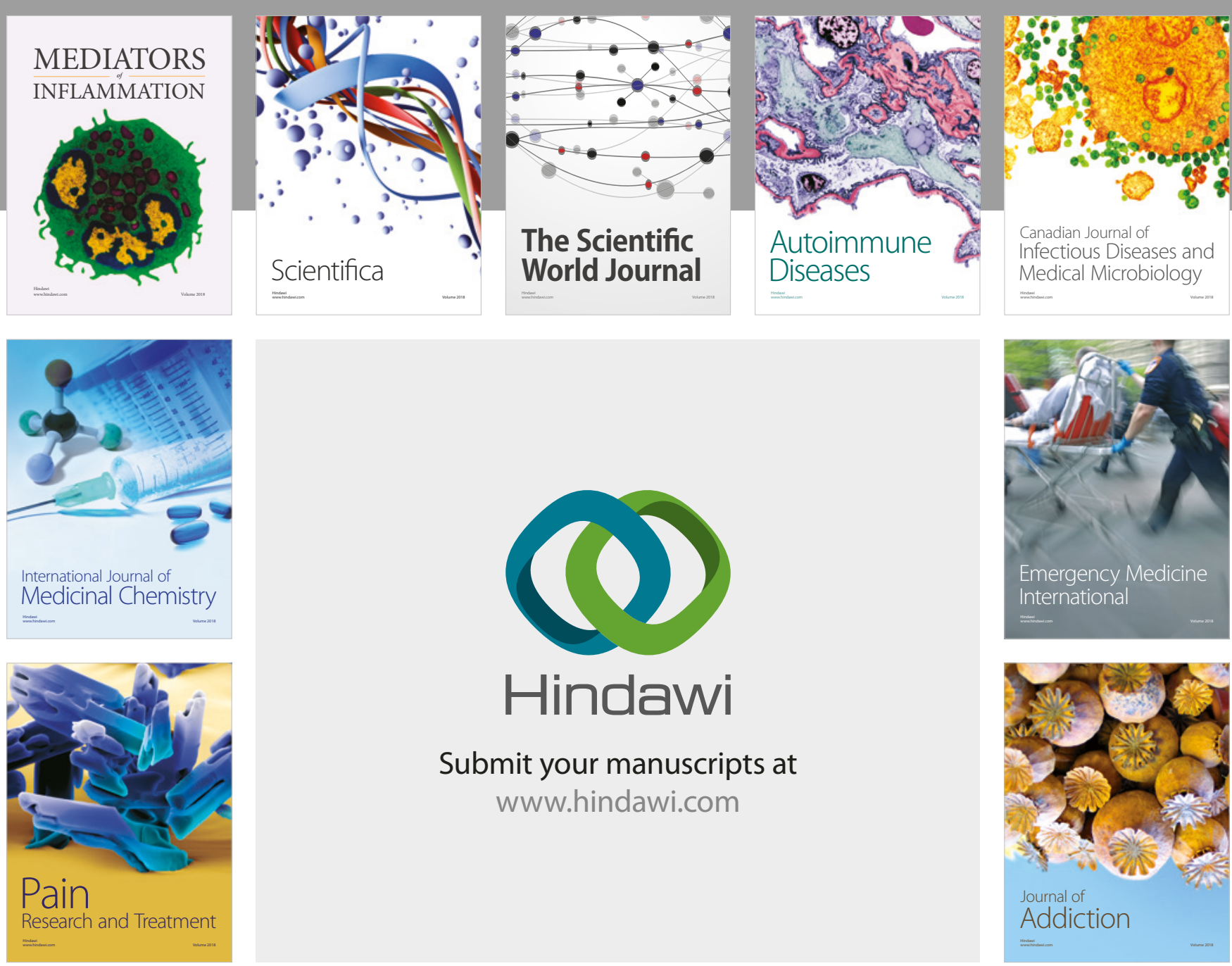

Canadian Journal of
Infectious Diseases and Medical Microbiology

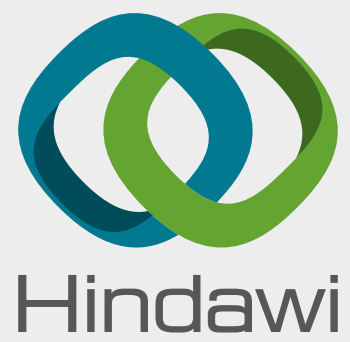

Submit your manuscripts at

www.hindawi.com
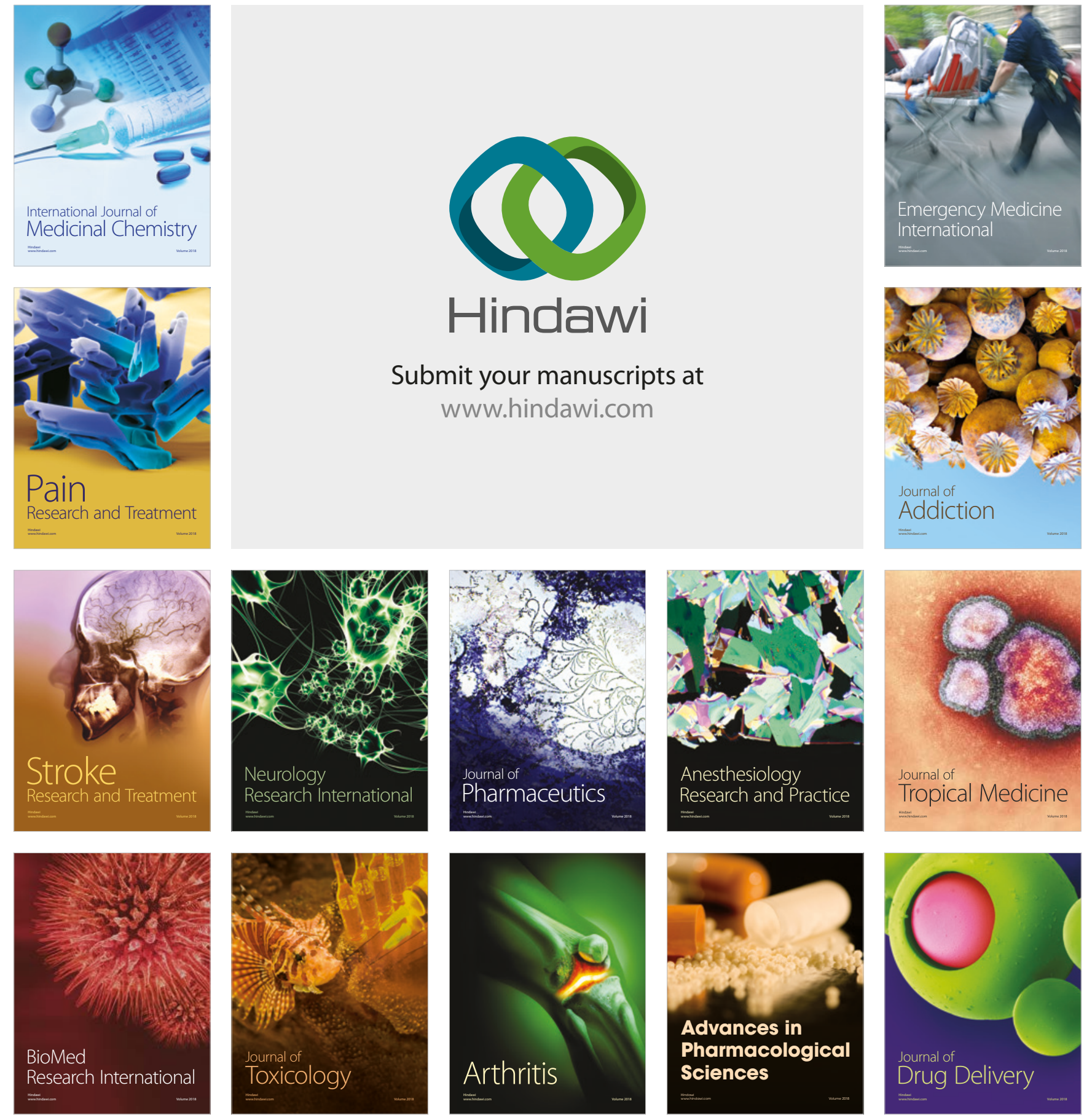